\title{
Determination of Heavy Rain Damage-Triggering Rainfall Criteria Based on Data Mining
}

\author{
Jongsung Kim ${ }^{1}$, Donghyun Kim ${ }^{1}$, Changhyun $\mathrm{Choi}^{2}$, Myungjin Lee ${ }^{1}$, Yonsoo Kim ${ }^{3}$, Hung Soo Kim ${ }^{1}$ \\ ${ }^{1}$ Department of Civil Engineering, Inha University, Incheon, 22212, South Korea \\ $5 \quad{ }^{2}$ Risk Management Office, KB Claims Survey and Adjusting, 06212, Seoul, Korea \\ ${ }^{3}$ RM Research institute, LIG System, 03130, Seoul, Korea
}

Correspondence to: Hung Soo Kim (sookim@inha.ac.kr)

\begin{abstract}
Heavy rainfall occurs over the Korean peninsula mainly because of typhoons and a localized heavy rainfall, leading to severe flooding and landslide risk. KMA (Korean Meteorological Administration) has the criteria for issuing a Heavy Rain
\end{abstract}

10 Advisory (HRA) over the peninsula even though each region or local government has different conditions in capability of disaster prevention (CDP) and different characteristics in rainfall and heavy rain damage. Therefore, the aim of this study is to suggest the methodology for the determination of Heavy rain Damage-Triggering Rainfall Criteria (HD-TRC) that HRA can be issued in each region. The study regions are local governments in Gyeonggi-province, Seoul-city, and Incheon-city in Korea. HD-TRC can be determined based on rainfall and heavy rain damage data. The data from 2005 to 2018 are collected and then

15 the data for flood or rainy season from June to September are extracted. The rainfall data is provided in KMA and heavy rain damage data during disaster periods (DPs) can be obtained from the statistical yearbook of natural disaster (SYND) published by MOIS (Minstry of Interior and Safety) every year. Training set of 2005 to 2014 is used for obtaining HD-TRC and test set of 2015 to 2018 is used for evaluating three criteria of HD-TRC, Advanced HD-TRC, and HRA. Analysis for determining the best criteria is performed through data mining processes as follows: (1) Maximum rainfalls in durations of 1 to $24-\mathrm{hr}\left(X_{1}\right)$ and antecedent rainfalls of 1 to 7-day $\left(X_{2}\right)$ are obtained and used as independent variables. Heavy rain damage data are divided into damage day (" 1 ”) and no damage day (“0”) used as dependent variables $(Y)$. Principal component analysis (PCA) is performed and PCs (principal components) are obtained as PC. $\mathrm{X}_{1}$ and PC. $\mathrm{X}_{2}$ for independent variables. Then Risk Index (RI) is defined as PC. $X_{1}+P C . X_{2}$ and RIs become the candidates for HD-TRC. The predicted damage $(\hat{Y})$ is obtained based on RIs and confusion matrix is constructed then the best HD-TRC is determined through the evaluation of classification performance.

25 (2) However, 'abnormal days' (ADs) in a DP that the damage is occurred exists. The ADs mean the days which we do not have rainfall or have small rainfall amount during DP. Say, ADs have too small rainfall to damage even during DP. The ADs are defined as days below rainfall of $20 \mathrm{~mm}$ and 5 cases of ADs are also defined as 0, 0 5, 0 10, 0 15, and 0 20mm in this study. We count total days in all the DPs and in ADs for a case. The ratio of ADs to total days during DPs could be the occurrence probability or prior probability (PP) of ADs for a case and 5 PPs are obtained. Also, the average AD for each case

30 can be obtained and defined as risk range (RR). Then we define Advanced HD-TRC using MCS (Monte Carlo Simulation) linked with PP, RR, and from HD-TRC for each case. Therefore, HD-TRC is determined based on RI and Advanced HD- 
TRC for each case based on PP and RR. Finally, three criteria of HD-TRC, Advanced HD-TRC, and HRA are compared based on performance evaluation by test set. As a result, Advanced HD-TRC shows the best performance and so the suggested methodology can be used for regional heavy rain damage warning information.

\section{Introduction}

The frequency of natural disaster and damage scale are increasing trend over the world due to climate change and rapid urbanization. In the last decade, total damage by natural disaster was 3.4 trillion KRW (Korean Won) (USD 2.83 billion) in Korea. Especially, the damage by heavy rain was 3.4 trillion KRW (USD 1.25 billion) (Ministry of the Interior and Safety, MOIS, 2018). Therefore, the structural measures such as dam, levee or dike, and flood control channel have been constructed while the nonstructural measures of natural or heavy rain disaster forecasting and warning system have been also used for the damage reduction. However, in recent, people are aware of the importance of the conservation of nature and the value of ecosystem and so these days, our preference is for the nonstructural measures rather than the structural measures. Forecasting and early warning system for flood or heavy rain damage is one of examples of the nonstructural measures which can give early warning to the affected people. This can provide information for preparing to match urgent needs with available resources and for emergency response according to an action plan then it can considerably reduce heavy rain loss and damage, and the loss of human lives.

However, the accuracy of forecasting and warning system is required in two aspects. First is about the accuracy of meteorological information which is forecasted by various models and the other is the accuracy of warning criteria. Weather forecasting has been studied for a long time and various models have been used for the future prospects of meteorological

50 information considering climate change (Kannan et al., 2010; Abbot et al, 2012; Mekanik et al, 2013; Abbot et al., 2014; Kim et al., 2014). Many researches have been also performed for the evaluation of flood and drought risks by using the future meteorological information (Kay et al., 2006; Dankers et al., 2008; Robert et al., 2012; Zbigniew et al., 2013). But the accuracy of long-term forecasting for the future can not be guaranteed because many uncertainties are involved in observations and information and so the study has concentrated on short-term forecasting of meteorological information using various statistical methods such as regression model, neural network model, machine learning, and so on (Chau et al., 2010; El-Shafie et al., 2011; Abhishek et al., 2012; Kim et al., 2013;Cramer et al., 2017; Mishra et al., 2018; Chatterjee et al., 2018; Luitel et al., 2018). While the researchers have interested in the studies for meteorological forecasting, there have not been enough studies to develop the warning criteria.

The early warning system for landslide has warning criteria according to earthquake intensity but there is no warning criteria

60 for heavy rainfall in Korea. Actually, the landslide and failure of slope are related to the localized heavy rainfall and typhoons mostly occurred in June to September. Therefore, the previous studies said that the warning criteria of landslide should be determined according to heavy rainfall and so the statistical, empirical, and satellite methods have been applied to determine the critical or threshold value of landslide-triggering heavy rainfall (Glade et al., 2000; Piciullo et al., 2016; Rossi et al., 2017; 
Lee et al., 2017). Also, the early warning for flood is determined by threshold value of flood discharge obtained from flood Forestieri et al., 2016; Miao et al., 2016; Sieq et al, 2017; Zhai et al., 2018; Sairam, 2019). However, the rainfall-runoff model can be used just for a specific region around the river or a river basin. There are statistical methods of rainfall ensemble and the relationship of IDF (Intensity-Duration-Frequency) curve and the return period for determination of critical rainfall (Kim et al., 2011; Bezak et al., 2015; Yang et al., 2016). The critical rainfall for improvement of Heavy Rain Advisory (HRA) or Heavy Rain Warning (HRW) is determined by the occurrence probability of damage in each rainfall duration obtained by Bayesian theory (Park et al., 2014; Montesarchio et al., 2015; Song et al., 2016; Cho et al., 2018; Jeong et al., 2017; Lopez et al, 2017; Choi et al., 2018; Lee et al., 2018; Kim et al., 2018). The previous studies have mostly suggested the criteria based on the specific rainfall intensity and this can explain for the localized heavy rainall but it is difficult to explain for relatively small amount of rainfall having long duration. In addition, the damage day was not considered in most of previous studies, and among them, there was no study considering the uncertainty that damage could occur even in small rainfall.

Therefore, this study considers rainfall intensities of 24 durations and antecedent rainfalls of 1 to 7 days for explanation of various rainfall events. Also this study consider the uncertainty of ADs additionally. The purposes of the study are to understand the regional rainfall and heavy rain damage characteristics based on data mining and to suggest Heavy rain Damage-Triggering Rainfall Criteria (HD-TRC) for each region or local government. Then we are going to propose Advanced HD-TRC through considering uncertainty of ADs stochastically.

\section{Heavy Rain Warning Criteria and Statistical Yearbook of Natural Disaster}

\subsection{Warning Criteria for Heavy Rain}

Early warning system has been studied and utilized in most of the countries to mitigate natural disaster risk. Especially, heavy

rain warnings are issued with the criteria when heavy rainfall is expected to cause serious damage, such as severe flooding and/or landslides. As can be seen in Table 1, heavy rain advisory and warning are announced by soil water index (SWI) and heavy rainfall intensity of the best segmentalized administrative district by JAM (Japan Meteorological Agency) in Japan. SWI is for the stored water quantity in soil and higher SWI describes higher disaster risk. Hong Kong Observatory (HKO) is operating early warning system of Amber, Red, and Black based on heavy rainfall intensity. Canada (http://www.weather.gc.ca) divided the region into three groups and is utilizing the early warning system for heavy rainfall. HRA and HRW are issued by KMA when the forecasted heavy rainfall intensity is above the criteria.

\section{Table 1.}

Japan, Hong Kong, and Canada are considering the regional characteristics for HRA or HRW while the same criteria over the Korean peninsular without consideration of local properties has been used for issuing HRA and HRW in Korea. In reality, each local government or region has different Capability of Disaster Prevention (CDP). When the same criteria for HRA is 
applied to A region having lower $\mathrm{CDP}$ and $\mathrm{B}$ region higher $\mathrm{CDP}$, the damage may be occurred in A region but not in $\mathrm{B}$ region. That is to say, A region can have damage even though HRA is not issued but B region does not have damage even though HRA is issued. If the regional characteristics are not properly reflected for HRA, this causes people to lose the trust for the criteria of HRA. Therefore, we may need the regional criteria of HRA which can consider heavy rainfall, heavy rain damage, and CDP characteristics of each local government. To do this, the methodology for derivation of Heavy rain DamageTriggering Rainfall Criteria (HD-TRC) that means the critical or threshold rainfall criteria in each region or local government which the damage can be occurred are suggested in this study.

\subsection{Statistical Yearbook of Natural Disaster}

105 The SYND (statistical yearbook of natural disaster) which records the data related to the damage occurred due to natural disaster is published by MOIS (Korean Ministry of the Interior and Safety) every year from 1985 to present. It is categorizing the damage data according to meteorological hazards such as typhoon, heavy rainfall, heavy snowfall, strong wind, ocean wave and so on. Damage data is also organized in SYND for each region such as si (city), gun (county), and gu (district). MOIS defines Disaster Period(DP) in SYND as HRA period issued by KMA and the damage is recorded for casualty, victims, public facility, and private facility during DP (see Table 2). When a rainfall event is moving over the regions, the event affects from a region that the first damage is occurred to the final damaged region and this moving period of an event is DP. However, there exists a certain region of no rainfall even during DP and so the damage could not be occurred in the region.

Table 2 is describing an example of heavy rain damage occurred from August 26, 2018 to September 1, 2018 for Nowondistrict in Seoul city and this is recorded in SYND published in 2019. There are the damage items, DP in the top of right side,

115 and total damage in the bottom of right side in SYND. Total damage was $317.94 \mathrm{KRW}$ in millions and KRW is KoRean Won (1USD=KRW/1,200). Therefore, all the damage and DP over the country are recorded in SYND and this study collected the heavy rain damage data and DP from 2005 to 2018 for local governments in Gyeonggi-province, Seoul-city, and Incheon-city (see a section 5.1).

Table 2.

120 The damage data and the damage days during DPs are collected for the study regions and Fig. 1 is showing the damage and damage days in all of the study regions (66 districts). The red line represents the no. of damage day and green bar is for the damage. Annual mean damage was about USD 38 million and the number of annual mean damage was 348 . The biggest damage and damage days or damage frequency were occurred in 2011 and the damage frequency in 2006 is similar with 2011 but the damage was relatively smaller than that of 2011. The damages and damage frequencies in 2014 and 2015 were very small and so we can know that it is describing drought years.

Figure 1. 


\subsection{Rainfall Data Collection}

Rainfall data is observed and managed by KMA, MOLIT (Ministry of Land, Infrastructure and Transport), and K-Water in Korea. Especially, the relatively long and reliable rainfall data record can be obtained from KMA. ASOS (Automated Surface

130 Observing System) and AWS (Automatic Weather System) are used for measuring meteorological data including rainfall. The rainfall data has been observed from 1970s by ASOS which has 101 stations in South Korea while the data observed from 2000s by AWS which has 501 stations. Therefore, this study uses the record of AWS which has more densely distributed stations and Thiessen polygon method is used for spatial distribution of the rainfall. The hourly rainfall data by AWS is collected from 2005 to 2018 and it is transformed to mean aerial precipitation of each region. Finally, this study collects maximum rainfalls in durations of 1 to 24-hr and antecedent rainfalls of 1 to 7 -day from hourly rainfalls for the administrative districts of each city, county, and district in Gyeonggi-province, Seoul-city, and Incheon-city, Korea.

\section{Analysis Methods for Determination of HD-TRC}

\subsection{Data Mining}

140 Data mining is the process to find the patterns and characteristics in large data sets involving methods at intersection of statistics, machine learning, and database system. It is not a simple technique and also called as KDD (knowledge-discovery in databases) (Hand, 2007; Olson, 2008). The overall processes for data mining are explained as follows (Hastie, 2009; Frank, 2011).

\section{(1) Data Extraction}

145 First, it is necessary to set the purpose of solving the problem. Based on the purpose of doing the analysis and deriving data characteristics, the selection and collection of raw data will follow.

\section{(2) Data Preprocessing}

Data preprocessing is the second step in data mining technique. This is used to transform the raw data into a useful and efficient

150 format. The phrase "garbage in, garbage out" is particularly applicable to data mining projects. If one use an incorrect data, the obtained result will definitely be incorrect. Thus data preprocessing refers to the process of supplementing raw data such as filling the missing data and removing the redundant data.

\section{(3) Data Transformation}

155 In order to utilize a meaningful data analysis, deriving a representative characteristic or sample data is deemed important. Representative characteristic or sample data are converted from a preprocessed data for analysis.

\section{(4) Data Analysis}


Data mining can be divided into three categories according to its purpose. The first category is association analysis, while the second category is classification. The last one is the regression prediction, wherein various analysis techniques are being used such as artificial neural networks (ANN), decision trees, and random forests. Algorithms uniquely developed by researchers can also be used for analysis

\section{(5) Evaluation and Interpretation}

165 The final step is to evaluate and interpret the analyzed results. Whether patterns and characteristics are suitable are judged through this process.

In this study, we tried to solve the classification problem related to prediction. The researchers performed data mining to derive the rain threshold which can forecast heavy rain damage from a large rainfall data. In the case of Step 4 of the data mining procedure, the most common classification techniques such as decision trees and random forest are widely used. However, this study proposes a new algorithm for deriving rain threshold for intuitive understanding.

\subsection{Monte Carlo simulation}

In general, deterministic model can find an exact solution, while stochastic model maybe can not. In this case, a series of random numbers can be repeatedly generated and simulated to find the answer to the approximation (Kroese, 2014). This method is called Monte Carlo simulation (MCS). MCS performs risk analysis by building models of possible results by substituting a range of a probability distribution for any factor with inherent uncertainty. Thus, MCS is useful for modeling with uncertainty or for problems with mathematically complex conditions (Nabian, 2017).

As an example, MCS can be used as a process for calculating pi(the ratio of the circumference of a circle to its diameter).

180 When calculating the area of a circle represented by $x^{2}+y^{2}=1$, the circle is completely contained within a square space with four in area. When a random number that satisfies this conditions $(-1 \leq x \leq 1$ and $-1 \leq y \leq 1)$ is generated in this space, the area of the circle can be roughly calculated by multiplying the ratio of the number of random numbers in the circle by the total area of 4 . If the number of randomly sampled random numbers increases, more accurate calculation results can be obtained. However, there may be some errors due to the stochastic method. In this study, the MCS was is used to express the

185 uncertainty of Ads (abnormal days) which the researchers have referred to as days without rainfall or have small rainfall amount during DP (Disaster period). Then, we examine the improvement of classification performance when the uncertainty is considered for HD-TRC. 


\subsection{Principal Component Analysis}

Principal component analysis is an analysis that derive new variables of small dimensions using a covariance matrix or a correlation matrix. The new variables are then called Principal Components and are not correlated with each other (Hotelling, 1933). In this study, the average vector for the set of independent variables $X=\left(X_{1}, X_{2}, \cdots, X_{m}\right)$ is designated as $\mu_{\text {and }}$ the covariance matrix is $\Sigma$, with the diagonal element of $\Sigma$ is the variance $\sigma_{1}^{2}, \sigma_{2}^{2}, \cdots, \sigma_{m}^{2}$ of each independent variable. The number of eigenvalues of the covariance matrix $\Sigma$ is $m$, with descending order of eigenvalues called as $\lambda_{1}, \lambda_{2}, \cdots, \lambda_{m}$. Also eigenvectors corresponding to each eigenvalue are called $e_{1}, e_{2}, \cdots, e_{m}$. The principal components are linear combinations with eigenvectors as coefficients (Wold et al., 1987). Covariance Matrix of principal component $\left(Y=\left(Y_{1}, Y_{2}, \cdots, Y_{m}\right)\right.$ ) are shown in Eq.(1) by characteristics of eigenvalue and eigenvector.

$$
\operatorname{Cov}(Y)=E^{t} \Sigma \mathrm{E}=\Lambda, \Lambda=\left(\begin{array}{ccc}
\lambda_{1} & \cdots & 0 \\
\vdots & \ddots & \vdots \\
0 & \cdots & \lambda_{m}
\end{array}\right)
$$

The eigenvalues are sorted by size, which means that some variances of the principal components may account for most of the sum of the variances of all the variables. Thus the variance of the entire independent variable set $X=\left(X_{1}, X_{2}, \cdots, X_{m}\right)$ can be well explained by the variance of the principal components $Y_{1}, Y_{2}, \cdots, Y_{k}$ of the minority of $k$ (Jolliffe, 2011).

In this study, principal component analysis was considered for the following reasons. First is that the heavy rain damage may be caused by short-term heavy rains, while small amount of rainfall with long-term may continue to cause damage. This study considers all of rainfall variables including the maximum rainfalls in durations of 1 to $24 \mathrm{hr}\left(X_{1}\right)$ and the antecedent rainfalls

205 of 1 to 7 days $\left(X_{2}\right)$ in order to explain the damage caused by various types of rainfall events. However, because this study considers many rainfall variables, it is difficult to determine the criteria as a representative rainfall threshold. Therefore, we tries to reduce all the variables into one principal component $(P C)$ which can represent both types of rainfall variables. Then, HD-TRC can be defined using $P C$ s.

\subsection{Evaluation of Classification Performance}

210 This study uses "1" for heavy rain damage days, and "0" for no damage days. In order to evaluate the performance in classification problem, the confusion matrix should be calculated (Fawcett, 2006). The confusion matrix is explained in Table 3 which has Positive(P) for " 1 " and Negative(N) for "0". If the predicted value $(\hat{Y})$ is 1 and the observed value $(Y)$ is 1 , it is called as True Positive(TP), and if $\hat{Y}$ is 0 and $Y$ is 0 , it is True Negative(TN). In addition, if $\hat{Y}$ is 1 and $Y$ is 0 , it is False Positive(FP), and if $\hat{Y}$ is 0 and $Y$ is 1 , it is False Negative(FN).

Table 3.

The performance evaluation indicators through confusion matrix can be defined and calculated (Table 4). These indicators are Accuracy, Error Rate, Sensitivity, Precision, and Specificity then, these can be used according to the purpose of the analysis (Powers, 2011).

\section{Table 4.}


220 There are 10,000 data. Say, $\mathrm{P}$ (" 1 ") is 1,000 and N ("0") is 9,000. This has imbalanced data structure. If we predict 10,000 data as 0 , accuracy is $90 \%$. because $\mathrm{N}$ is 9,000 . However, sensitivity is $0 \%$. Therefore, it is difficult to evaluate classification performance when one indicator is used and so combinations of indicators such as AUC, ROC curve, and F1-score should be used.

The ROC (Receiver operating characteristics) curve is created by plotting the Sensitivity against the 1-Specificity at various threshold settings. The ROC curve is a graphical plot that illustrates the diagnostic ability of a binary classifier system as its discrimination threshold is varied. The area under the curve (AUC) of the ROC curve is the criterion for verification. Fig. 2 shows the concept of ROC curve and AUC. The AUC values are varied from 0.5 to 1 and closer to 1 means better classification performance. If we see Fig 2, the yellow polygon with $\mathrm{AUC}=0.95$ has bigger area than the blue polygon with AUC $=0.50$. Due to its greater advantage, AUC is widely used as a representative performance evaluation indicator for comparing the absolute predictive performance (Choi, 2018). In general, it is appropriate to use AUC for a performance indicator of a balanced data. However, when the data is imbalanced, it is difficult to evaluate the performance correctly using AUC.

F1-score is a performance evaluation indicator that can be more accurately evaluated when the data is unbalanced in binary classification. As indicated by Sasaki, 2007, F1 score shown in Eq. 2, can be calculated through the harmonic mean of the precision and recall.

Figure 2.

$$
\mathrm{F}-\mathrm{score}=\frac{\left(1+\beta^{2}\right)(\text { Precision } \times \text { Sensitivity })}{\left(\beta^{2} \text { Precision }+ \text { Sensitivity }\right)}
$$

$\beta$ is generally defined as 1 in F-Score, and thus, it is called F1-Score. In order to verify if F1-score is appropriate as a performance measure in the imbalanced data, Saito (2015) applied several evaluation indicators in both balanced data and imbalanced data. As a result, most performance measure have shown equal performance in the balanced data $(\mathrm{P}: 1,000, \mathrm{~N}$ : $1,000)$ and imbalanced data $(\mathrm{P}: 1000, \mathrm{~N}: 10,000)$. However it was identified that the classification performance of PrecisionRecall Curve has changed in imbalanced data. Therefore, this study uses F1-score which includes precision and recall as the performance evaluation indicator.

\section{4. Analysis Procedure for Determination of HD-TRC}

\subsection{Analysis Procedure for HD-TRC}

\subsubsection{Step 1 : Dependent and independent variables}

Heavy rain damage and rainfall data are collected from MOIS and KMA then dependent and independent variables are determined as shown in Fig. 3 and Table 5. The procedure in Fig. 3 is explained as follows: 
(1) Daily damage data obtained during DP is divided into two groups of damage day and no damage day. Damage day is represented as 1 and no damage day as 0 . These 1 and 0 become dependent variable, $Y$ (also, see Fig. 8).

(2) Hourly rainfall data collected from KMA is transformed to mean aerial rainfall by Thiessen polygon method. Then, maximum rainfalls in durations of 1 to 24-hr( $\left.X_{1}\right)$ and antecedent rainfalls of 1 to $7-\operatorname{day}\left(X_{2}\right)$ are obtained and these become independent variables of $X_{1}$ and $X_{2}$.

(3) Thus, we establish dependent variable $Y$ and independent variables $X=X_{1}+X_{2}$. Also, the variables are divided into training set and test set.

\section{Figure 3 .}

Table 5.

\subsubsection{Step 2 : Rain index and performance test}

260 The best HD-TRC is determined in this step by performance test for training set. Its procedure is explained in Fig. 4 according to following steps:

(1) The variables of $Y$ and $X$ for rainy season of June to September are extracted through preprocessing of the data

(2) Principal component analysis (PCA) is performed for $X_{1}$ and $X_{2}$ then one principal component (PC) for $X_{1}$ and one for $X_{2}$ are obtained as PC. $X_{1}$ and PC. $X_{2}$. The sum of two PCs are defined as Rain Index (RI), say, RI $=P C . X_{1}+P C . X_{2}$.

(3) All the RIs in training set become the candidates of HD-TRC. If RI at the point of time we want to predict is greater than RI which is a candidate of HD-TRC, we predict the damage will be occurred. Then the confusion matrix for Obs. $(Y)$ and Pred. $(\hat{Y})$ is constructed and the classification performance test is conducted by F1-score for the evaluation of RI and the determination of HD-TRC. The RI having the best performance is determined as HD-TRC of the target region.

Figure 4 .

\subsection{Analysis Procedure for Advanced HD-TRC}

DP is defined as the period that heavy rain damage is occurred in SYND, that is to say, the period of HRA or HRW. Abnormal days(ADs) is also defined as the days which we do not have rainfall or have small rainfall amount or depth during DP(see (1) and (4) of Fig. 5). If ADs are included during DP, the prediction error of damage occurrence can be leaded. Therefore, this section defines Advanced HD-TRC considering uncertainty of ADs as explained in Fig. 5 as follows:

(1), (2), (3) ADs of 5 cases are defined according to rainfall depth from 0 to $20 \mathrm{~mm}$ during DPs. ADs of Case 1 is for no rainfall days during DPs, Case 2 is for rainfall days of $0 \sim 5 \mathrm{~mm}$, and Case $3 \sim 5$ for rainfall days of each rainfall depth in (1). The 
number of $N$ ADs during DPs is counted for each case and total number of days for all DPs $(M)$ is also counted. Then the ratio of $N / M$ is defined as Prior Probability (PP).

(4), (5) ADs for the same DPs of each case are obtained and ADs in DPs are averaged for each case. The averaged AD for each case can be rounded as an integer value. This averaged $\mathrm{AD}$ value is defined as Risk Range (RR). Here, $\mathrm{PP}$ is the occurrence probability of $\mathrm{AD}$ and $\mathrm{RR}$ is the occurrence range of $\mathrm{AD}$.

(6) We can know DP if the heavy rain damage was already occurred but we can not know DP at the starting point of time for the damage prediction. Therefore, the damage is predicted by assuming the damage will be occurred when the bigger rainfall than HD-TRC is produced and we consider the probability and the range that $\mathrm{AD}$ is included. The random number which is the probability is generated for the days corresponding to RR. The generated probability by MSC is compared with PP then the predicted damage occurrence is determined (also, see a section 5.4 and Fig. 14). Therefore, Advanced HD-TRC is defined according to PP and RR estimated in each Case.

Figure 5.

\subsection{Comparative Analysis for Determination of the Best Criteria}

This section evaluates three criteria of HD-TRC, Advanced HD-TRC, and HRA and the best one is selected. the evaluation procedure is explained as follows (Fig. 6).

(1) HD-TRC, Advanced HD-TRC, and Heavy rain advisory(HRA) are applied to test set and we calculate performance indicators such as F1-Score and AUROC by confusion matrix.

(2) Then the best criteria having the best performance is determined.

\section{Figure 6.}

\section{Determination of Heavy Rain Damage-Triggering Rainfall Criteria}

\subsection{Study Region}

The methodology suggested in this study is applied to the local governments of the metropolitan area. Say, Gyeonggi-province has 25 local governments or districts, Seoul-city 31, and Incheon-city 10 (Fig. 7). The study investigated the damage history for each region and district then obtained the frequency and the average frequency of heavy rain damage for each region and administrative district (Table 6). However, the damage history is not enough to suggest HD-TRCs for whole local governments or districts of city, county, and district. Therefore, this study combine all the data of local governments for Gyeonggi-province, Seoul-city, and Incheon-city and suggests HD-TRCs for three regions.

Table 6.

Figure 7. 


\subsection{Data Preparation}

310

\subsubsection{Dependent variable}

As mentioned in a section 4.1.1, daily heavy rain damage data during DP is obtained by SYND from 2005 to 2018. Then the dependent variable, Y of " 1 " and " 0 " for damage day and no damage day is obtained and this is explained in Fig. 8. Blue color represents damage days of DP and other days has no damage.

\section{Figure 8.}

\section{$315 \quad 5.2 .2$ Independent variable}

There are 66 administrative districts and 103 stations of AWS in three regions of Gyeonggi-province, Seoul-city, and Incheoncity. About 4.7 stations affect the each district and hourly rainfalls from 103 stations are collected from 2005 to 2018. Fig. 9 shows Thiessen polygon for the estimation of mean aerial rainfall and daily rainfall variable is obtained for each district. Then, the independent variables of maximum rainfalls in durations of 1 to 24-hr $\left(X_{1}\right)$ and antecedent rainfalls of 1 to 7 -day $\left(X_{2}\right)$ are obtained and the variables are grouped into two sets of training set (2005 to 2014) and test set (2015 to 2018).

Figure 9.

\subsection{Determination of the best HD-TRC by performance test for training set}

\subsubsection{Data preprocessing}

Annual rainfall and the number of damage day are compared for examination of similarity between them in Fig. 10 which is plotted by standardized values because of scale difference. There are drought periods in 2014 to 2015 . Especially, there was an extreme flood period in 2011 and an extreme drought period in 2014 to 2015. However, in 2006, annual rainfall was generally in average value while the number of day showed relatively higher value. This means that the small rainfall duration lasted long even annual rainfall was average value and the rain damage was frequently occurred. Therefore, mostly, the heavy rain damage is increased as the rainfall is increased and so understanding damage occurrence based on the heavy rainfall is needed for HD-TRC.

Figure 10.

335 Because the number of damage days are much smaller than that of no damage days, it is very difficult to understand the proper HD-TRC by using all the damage data. The study examines the monthly damage history to see the damage period during 2005 to 2018 and finds the damage has been occurred mainly during rainy days in rainy season of June to September (Fig. 11). Therefore, we collect the data for rainy season and determine HD-TRC by using collected data and suggested methodology.

\section{Figure 11.}


As we can see in Table 7, the number of damage and no damage days for rainy season are smaller than that for whole years (2005 to 2014). Especially, the number of no damage days " 0 " is greatly reduced but " 1 " is a little reduced. Say, the number of " 1 " is reduced by $15 \%$ but " 0 " which we do not need by $90 \%$ and so if we just consider rainy season the analysis becomes more easier.

\subsubsection{Rain Index}

There are too many independent variables to suggest them as HD-TRC and so principal component analysis (PCA) is used for deriving the principal components of $P C . X_{1}$ from maximum rainfalls of 1 to 24 -hr duration and of $P C . X_{2}$ from antecedent rainfalls of 1 to 7-day. Then rain index (RI) is defined as following equation of (3).

$$
P C . X_{1}+P C . X_{2}=R I
$$

In general, when the number of principal component is determined, the cumulative variance of each variable should be over

$80 \%$ for minimizing information loss and reducing the variables. As a result, we identify the cumulative variances of $P C . X_{1}$ and $P C . X_{2}$ are over $80 \%$ (Table 8 ) and this means there is no problem to reduce the variables as two principal components. That is to say, $P C . X_{1}$ and $P C . X_{2}$ are estimated and RIs are also obtained for each region. In training set, all RIs can be used for examining daily damage occurrence and regarded as the candidates for the determination of HD-TRC.

Table 8.

\subsubsection{Determination of HD-TRC by Rain Index}

The daily damage data in training set is classified as "0" and " 1 " for the construction of confusion matrix and evaluation indices in Table 4 are calculated for the classification performance. For an example, RI 1 becomes a criteria candidate and other RIs are compared to RI 1 then the results of comparison will be the predicted damage occurrence $(\widehat{Y})$. Next RI 2 will be another criteria candidate then others are compared to RI 2 for obtaining the other predicted damage occurrence. In this way, the predicted damage occurrence is estimated and then the confusion matrix is obtained based on $Y$ and $\hat{Y}$.

The evaluation indices such as Sensitivity, Specificity, and Precision are calculated from the confusion matrix.

Figure 12 
and then the performance measures of F1-score by Sensitivity and Precision, and AUC by Sensitivity and Specificity are estimated. There are the number of data for " 1 " and " 0 " in each region. Total epoch of Gyeonggi-province has 18,055, Seoulcity 13,295, and Incheon-city 5,069. Here, epoch means that all the criteria candidates are evaluated as much as the number of data. The criteria candidate which has the largest F1-score becomes HD-TRC. Fig. 12 is showing the F1-score in all of epoch on each region. Also the red points are expressed criteria candidates which have the largest F1-score. Therefore, HD-TRCs are determined based on F1-score for the regions (Table 9).

Table 9.

Fig. 13 is showing RIs, the determined HD-TRC, and the predicted damage occurrence on training set for each region. Red is for observed damage day, blue is for observed no damage day, triangle is for predicted damage day, and cross is for predicted no damage day. Therefore, the classification can be obtained. That is, red triangle is for observed and predicted damage days (TP), blue triangle is for observed no damage day and predicted damage day (FP), red cross is for observed damage day and predicted no damage day (FN), and blue cross is for observed and predicted no damage days (TN). The black line is for the determined HD-TRC for each region. The confusion matrix is constructed by the classification results (Table 10).

\section{Figure 13}

RIs above the line of a determined HD-TRC in Figure 14 mean the predicted damage occurrence represented by triangle and RIs below the HD-TRC mean the predicted no damage occurrence by cross. The HD-TRC for each region is determined based on the best classification performance which has maximum F1-score. However, if we see Table 10, there are still the number of FN and FP, and also it can be seen in red cross(FN) and blue triangle(FP). FN still includes ADs and FP includes no damage days even though heavy rainfall was occurred. Therefore, this study considers ADs in FN to improve the predictability or classification performance and analyzes ADs in a section 5.4. The improved HD-TRC is called Advanced HD-TRC. However, FP is not reconsidered here. The reasons why no damage, even during heavy rainfall, exists are different regional characteristics such as CDP, urbanization, resilience, and so on.

\section{Table 10.}

\subsection{Determination of Advanced HD-TRC by Risk Range}

This study defines ADs as below daily rainfall depth of $20 \mathrm{~mm}$ during DP and 5 cases as 0,0 to 5,0 to 10,0 to 15 , and 0 to $20 \mathrm{~mm}$ in Table 11. Total number of days for DPs (M) and Total number of Ads (N) are counted (see (2) and (4) of Fig. 5).

400 Then prior probability (PP) and risk range (RR) are also defined in Table 11 and Figure 6. PP is the probability that AD is occurred and $\mathrm{RR}$ is the range that $\mathrm{AD}$ is occurred as explained in a section 4.2. We use all the raw data without preprocessing to identify more exact PP and RR in training set in this section while we used the data of June to September with preprocessing for HD-TRC in section 5.3.1. 


\section{Table 11.}

Actually we do not know AD and DP for the future but we know PP and RR from observations. Therefore the study applies MCS for probabilistically obtaining the final predicted damage occurrence, $\hat{Y}$ by using PP and RR. An example is described for the case 2 in Table 11. Case 2 is for daily rainfall of 0 to $5 \mathrm{~mm}$, for $P P=0.3198$ (about 0.32 ), and $R R=2$ days obtained from training set. Fig. 14 is analysis procedure for an example. The first column is for row number, and second is for the damage occurrence, $\hat{Y}$ which can be predicted by the comparison of RI from test set with the determined HD-TRC in training set. Third is for the generated probability $(\mathrm{P})$ which $\mathrm{AD}$ can be occurred in test set and $\mathrm{AD}$ is corresponding to $\mathrm{RR}$. The last column is for the final predicted damage occurrence, $\widehat{Y}^{\prime}$ obtained by the comparison of PP and P.

If we see Fig. 14, two predicted damage days, $\widehat{Y}$ can be found in the row numbers of 4 (predicted damage day(1)) and 6 (predicted damage day(2)) as $\hat{Y}=1$. RR is 2 days and this is regarded as \pm 2 days around $\hat{Y}=1$. Therefore, $\operatorname{RR}(1)$ and $\operatorname{RR}(2)$ 415 can be considered as the risk range based on predicted damage day(1) of $\hat{Y}=1$ and also $\operatorname{RR}(2)$ and $\operatorname{RR}(3)$ based on predicted damage day(2). The random numbers are generated for the days corresponding to RR and this becomes the probability $(\mathrm{P})$ that $\mathrm{AD}$ is occurred. However, $\mathrm{RR}(2)$ in predicted damage day(1) is overlapped with predicted damage day(2) and so the random number of 0.24 is produced just for one day. That is, $\mathrm{P}$ is generated and compared with PP for the determination of $\widehat{Y}^{\prime}$. If we see Figure 15, since the row numbers of 1 and 9 are not included in RR, $\widehat{Y}^{\prime}$ becomes 0 . The generated random numbers for the row numbers of $2,5,7$, and 8 are less than $\mathrm{PP}=0.32$ and so $\hat{Y}=0$ becomes $\hat{Y}^{\prime}=1$. In the row 3 , since $\mathrm{P}=0.84$ is greater than $\mathrm{PP}=0.32, \widehat{Y^{\prime}}=0 . \widehat{Y}$ is 1 in the rows of 4 and 6 and so $\hat{Y}^{\prime}$ maintains 1 . In this way, the analysis is performed for 5 cases and this procedure is defined as Advanced HD-TRC. That is to say, Advanced HD-TRC considers uncertainty of AD by applying MCS and obtains more improved $\hat{Y}^{\prime}$.

\section{Figure 14}

\subsection{Determination of the Best Criteria by the Performance Evaluation}

The HD-TRC and Advanced HD-TRC for each Case were determined in training set (2005 2014). Also, these criteria were evaluated in test set $(2015 \sim 2018)$ then the best criteria was obtained. All the results including HRA are tabulated in tables 12 to 14. As the results, HD-TRC shows much better than HRA of KMA in its performance. If we see F1-score to compare HDTRC with HRA, the performance of HD-TRC on Gyeonggi-province is improved 23.17\%, Seoul-city 5.06\%, and Incheoncity 19.37\%. F1-scores of Advanced HD-TRCs for 5 Cases show better than HRA and HD-TRC. Advanced HD-TRC for Case 4 has the best performance in Gyeonggi-province and Incheon-city, and one for Case 5 has in Seoul-city. Therefore, the proper best criteria for warning and forecasting of heavy rain damage will be Advanced HD-TRC 4 in Gyeonggi-province and Incheon-city, and Advanced HD-TRC 5 in Seoul-city.

Table 12. 


\section{Table 13.}

Table 14.

\section{Summary and conclusions}

440 We have suggested a methodology for the derivation of the rainfall criteria which heavy rain damage can occur. To do this, data mining process was used and the performance of the derived rainfall criteria was evaluated systematically. Initial step includes defining Rain Index (RI) by applying principal component analysis for various rainfall variables and all RIs were considered as candidates of HD-TRC. The performance evaluation for RIs based on heavy rain damage data was carried out and the best HD-TRC was selected. However, even though we do not have rainfall or have small rainfall amount during DP, 'abnormal days'(ADs) that the damage occurs exist. Therefore this study considered HD-TRC and the occurrence probability of ADs using Monte Carlo simulation. Then we defined this process as Advanced HD-TRC. Then, three criteria of HRA of KMA, HD-TRC, and Advanced HD-TRC were compared through classification performance and the main results of this study are summarized as follows:

(i) The best HD-TRCs in regions showed a value of 5.030 in Gyeonggi-province, 10.881 in Seoul-city, and 5.109 in Incheoncity.

(ii) The performance of HD-TRC by F1-score has improved compared to the HRA by $23.17 \%$ in Gyeonggi-province, $5.06 \%$ in Seoul-city, and $19.37 \%$ in Incheon-city.

(iii) The performance of the 5 Advanced HD-TRCs by F1-score has improved compared to the performance of HD-TRC for each region.

(iv) The best criteria for each region were selected as Advanced HD-TRC 4 in both Gyeonggi-province and Incheon-city, and Advanced HD-TRC 5 in Seoul-city.

(v) The performance of the best criteria for each region was evaluated by F1-score and AUC. The results are as follows: F1-score showed 37.94\% in Gyeonggi-province, 30.04\% in Seoul-city, 40\% in Incheon-city.

AUC showed $73.36 \%$ in Gyeonggi-province, $73.40 \%$ in Seoul-city, and $76.74 \%$ in Incheon-city.

Upon calculating the F1-scores, HD-TRC showed an improvement of 15\% on average compared to HRA of KMA in all regions, while Advanced HD-TRC showed a $21 \%$ improvement. In addition, if we see evaluation results by AUC, HD-TRC was improved by $7.8 \%$ compared to HRA, while the Advanced HD-TRC improved by 20\%. F1-score, which is known to be suitable for imbalanced data, was used as a performance measure. However, F1-score is a relative evaluation indicator, that is, it

465 depends on the degree of imbalance in the data. Therefore, AUC, which is an absolute evaluation indicator was also used in this study.

It was identified that the HD-TRC of Seoul City is the highest and the HD-TRC of Gyeonggi Province is the lowest. This signifies that the region with a high HD-TRC means that the damage can occur on relatively high rainfall intensity. It could be 
judged that roughly, the CDP of Seoul City is higher than that of Incheon City and Gyeonggi Province. In this study, since only the rainfall and damage data were used, the relative CDP could be roughly estimated. However if additional factors such as socio-economic factors or disaster prevention projects in future research are to be considered, it could be expected that the CDP in region can be explicitly identified. If the results of this study would be used for an early warning system, it is possible to support the disaster managers through predicting the occurrence of heavy rain damage. Thus, it is expected that the suggested methodology will contribute in establishing safe environment of our life from natural disaster such as heavy rainfall.

\section{Acknowledgement}

This research was supported by a grant(2018-MOIS31-009) from Fundamental Technology Development Program for Ext reme Disaster Response funded by Korean Ministry of Interior and Safety(MOIS).

\section{References}

Abbot, J. and Marohasy, J.: Application of artificial neural networks to rainfall forecasting in Queensland, Australia. Advances in Atmospheric Sciences, 29, 717-730, https://doi.org/10.1007/s00376-012-1259-9, 2012.

Abbot, J. and Marohasy, J.: Input selection and optimisation for monthly rainfall forecasting in Queensland, Australia, using artificial neural networks. Atmospheric Research, 138, 166-178, https://doi.org/10.1016/j.atmosres.2013.11.002, 2014.

485 Abhishek, K., Kumar, A., Ranjan, R. and Kumar, S.: A rainfall prediction model using artificial neural network. IEEE Control and System Graduate Research Colloquium, 82-87, https://doi.org/10.1109/ICSGRC.2012.6287140, 2012.

Alfieri, L. and Thielen, J.: A European precipitation index for extreme rain-storm and flash flood early warning. Meteorological Applications, 22, 3-13, https://doi.org/10.1002/met.1328, 2015.

Beguería, S. and Vicente-Serrano, S. M.: Mapping the hazard of extreme rainfall by peaks over threshold extreme value analysis and spatial regression techniques. Journal of applied meteorology and climatology 2006, 45, https://doi.org/10.1175/JAM2324.1, 108-124.

Bezak, N., Šraj, M., Brilly, M. and Mikoš, M.: Return Period Determination for Several Extreme Rainfall-Induced Events Using the IDF Relationship Obtained via Copulas. In 12th International Conference on Applications of Statistics and Probability in Civil Engineering, ICASP12, 324, 1-8, https://doi.org/10.14288/1.0076104, 2015.

495 Chatterjee, S., Datta, B., Sen, S., Dey, N. and Debnath, N. C.: Rainfall prediction using hybrid neural network approach. In 2018 2nd International Conference on Recent Advances in Signal Processing, Telecommunications \& Computing (SigTelCom), 67-72, https://doi.org/10.1109/SIGTELCOM.2018.8325807, 2018.

Chau, K. W. and Wu, C. L.: A hybrid model coupled with singular spectrum analysis for daily rainfall prediction. Journal of Hydroinformatics, 12, 458-473, https://doi.org/10.2166/hydro.2010.032, 2010. 
https://doi.org/10.5194/nhess-2020-295

Preprint. Discussion started: 9 October 2020

(c) Author(s) 2020. CC BY 4.0 License.

500 Cho, J. W., Bae, C. Y. and Kang, H. S.: Development and application of urban flood alert criteria considering damage records and runoff characteristics., Journal of Korea Water Resources Association, 51(1), 1-10, 2018.

Choi, C., Kim, J., Kim, J., Kim, D., Bae, Y. and Kim, H. S.: Development of heavy rain damage prediction model using machine learning based on big data., Advances in Meteorology, https://doi.org/10.1155/2018/5024930, 2018.

Cramer, S., Kampouridis, M., Freitas, A. A. and Alexandridis, A. K.: An extensive evaluation of seven machine learning methods for rainfall prediction in weather derivatives., Expert Systems with Applications, 85, 169-181, https://doi.org/10.1016/j.eswa.2017.05.029, 2017.

Dankers, R. and Feyen, L.: Climate change impact on flood hazard in Europe: An assessment based on high-resolution climate simulations., Journal of Geophysical Research: Atmospheres, 113, https://doi:10.1029/2007JD009719, 2008

El-Shafie, A., Jaafer, O. and Akrami, S. A.: Adaptive neuro-fuzzy inference system based model for rainfall forecasting in

510 Klang River., Malaysia.: International Journal of Physical Sciences, 6, 2875-2888, 2011.

Fawcett, T.: An introduction to ROC analysis., Pattern recognition letters, 27, 861-874, https://doi.org/10.1016/j.patrec.2005.10.010, 2006.

Forestieri, A., Caracciolo, D., Arnone, E. and Noto, L. V.: Derivation of rainfall thresholds for flash flood warning in a Sicilian basin using a hydrological model., Procedia Engineering, 154, 818-825, https://doi.org/10.1016/j.proeng.2016.07.413, 2016.

515 Frank, E. and Hall, M. A.: Data mining: practical machine learning tools and techniques., Morgan Kaufmann, 2011.

Glade, T., Crozier, M., Smith, P.: Applying probability determination to refine landslide-triggering rainfall thresholds using an empirical "Antecedent Daily Rainfall Model"., Pure and Applied Geophysics, 157, 1059-1079, https://doi.org/10.1007/s000240050017, 2000.

Hand, D. J.: Principles of data mining., Drug safety, 30, 621-622, https://doi.org/10.1002/9781118445112.stat06466.pub2, 5202007.

Hastie, T., Tibshirani, R. and Friedman, J.: The elements of statistical learning: data mining, inference, and prediction, Springer Science \& Business Media., 2009.

Hotelling, H.: Analysis of a complex of statistical variables into principal components., Journal of educational psychology, 24, 417-441, https://doi.org/10.1037/h0071325, 1933.

525 http://www.weather.go.kr

http://www.weather.gc.ca

https://www.hko.gov.hk

https://www.jma.go.jp

Jeong, M. S.; Oak, Y. S.; Lee, Y. K.; Lee, Y. S.; Park, M. R.; Lee, C. H. Estimation of Disaster Prevention Target Rainfall 530 according to Urban Disaster Prevention Performance., Journal of the Korea Academia-Industrial cooperation Society, 18, 101110, https://doi.org/10.5762/KAIS.2017.18.4.101, 2017.

Jolliffe, I.: Principal component analysis., Springer Berlin Heidelberg, 2011. 
https://doi.org/10.5194/nhess-2020-295

Preprint. Discussion started: 9 October 2020

(c) Author(s) 2020. CC BY 4.0 License.

Kannan, M., Prabhakaran, S. and Ramachandran, P.: Rainfall forecasting using data mining technique., International Journal of Engineering and Technology, 2, 397-401, 2010.

Kay, A. L., Jones, R. G. and Reynard, N. S.: RCM rainfall for UK flood frequency estimation. II., Climate change results. Journal of hydrology, 318, 163-172, https://doi.org/10.1016/j.jhydrol.2005.06.013, 2006.

Kim, H. S. Hydrology., Ji Woo Books, 2017.

Kim, J. S., Choi, C. H., Kim, D. H., Joo, H. J., Kim, J. W. and Kim, H. S.: Establishment of Hazard-triggering Rainfall According to Heavy Rain Damage Scale: Focused on Gyeonggi-do., Journal of Climate Research, 13, 297-311, 540 https://doi.org/10.14383/cri.2018.13.4.297, 2018.

Kim, S., Kwak, J., Kim, H. S., Kim, Y., Kang, N., Hong, S. J. and Lee, J.: A regionalization of downscaled GCM data considering geographical features in a mountainous area. Advances in Meteorology 2014, https://doi.org/10.1155/2014/473167, 2014.

Kim, Y. H., Choi, D. Y., Chang, D. E., Yoo, H. D. and Jin, G. B.: An improvement on the criteria of special weather report

545 for heavy rain considering the possibility of rainfall damage and the recent meteorological characteristics., Atmosphere, 21, 481-495, https://doi.org/10.14191/Atmos.2011.21.4.481, 2011.

Kim, Y., Kang, N., Kim, S. and Kim, H.: Evaluation for snowfall depth forecasting using neural network and multiple regression models., Journal of Korean Society of Hazard Mitigation, 13, 269-280, https://doi.org/10.9798/KOSHAM.2013.13.2.269, 2013.

550 Kroese, D. P., Brereton, T., Taimre, T. and Botev, Z. I.: Why the Monte Carlo method is so important today., Wiley Interdisciplinary Reviews: Computational Statistics, 6, 386-392, https://doi.org/10.1002/wics.1314, 2014.

Kundzewicz, Z. W., Kanae, S., Seneviratne, S. I., Handmer, J., Nicholls, N., Peduzzi, P., ... and Muir-Wood, R.: Flood risk and climate change: global and regional perspectives., Hydrological Sciences Journal, 59, 1-28, https://doi.org/10.1080/02626667.2013.857411, 2013.

555 Lee, J. S. and Kim, Y. T.: Development of Optimum Rainfall Threshold to Predict of Rainfall-induced Landslides Occurrence., Journal of Korean Society of Hazard Mitigation, 17, 333-340, https://doi.org/10.9798/KOSHAM.2017.17.6.333, 2017.

Lee, S. H., Kang, D. H., Sik, B. and Sik, B. A Study on the Method of Calculating the Threshold Rainfall for Rainfall Impact Forecasting., Journal of the Korean Society of Hazard Mitigation, 18, 93-102, https://doi.org/10.9798/KOSHAM.2018.18.7.93, 2018.

560 Lopez, M. G., Di Baldassarre, G. and Seibert, J.: Impact of social preparedness on flood early warning systems., Water Resources Research, 53, 522-534, https://doi.org/10.1002/2016WR019387, 2017.

Luitel, B., Villarini, G. and Vecchi, G. A.: Verification of the skill of numerical weather prediction models in forecasting rainfall from US landfalling tropical cyclones., Journal of hydrology, 556, 1026-1037, https://doi.org/10.1016/j.jhydrol.2016.09.019, 2018. 
Mekanik, F., Imteaz, M. A., Gato-Trinidad, S. and Elmahdi, A.: Multiple regression and Artificial Neural Network for longterm rainfall forecasting using large scale climate modes., Journal of Hydrology, 503, 11-21, https://doi.org/10.1016/j.jhydrol.2013.08.035, 2013.

Miao, Q., Yang, D., Yang, H. and Li, Z. Establishing a rainfall threshold for flash flood warnings in China's mountainous areas based on a distributed hydrological model., Journal of hydrology, 541, 371-386, https://doi.org/10.1016/j.jhydrol.2016.04.054, 2016.

Ministry of the Interior and Safety(MOIS). The statistical yearbook of natural disaster., 2018.

Mishra, N., Soni, H. K., Sharma, S. and Upadhyay, A. K.: Development and analysis of artificial neural network models for rainfall prediction by using time-series data., International Journal of Intelligent Systems and Applications, 11, 16-23, https://doi.org/10.5815/ijisa.2018.01.03, 2018.

575 Montesarchio, V., Lombardo, F. and Napolitano, F.: Rainfall thresholds and flood warning: an operative case study., Natural Hazards and Earth System Sciences, 9, 135-144, https://doi.org/10.5194/nhess-9-135-2009, 2009.

Montesarchio, V., Napolitano, F., Rianna, M., Ridolfi, E., Russo, F. and Sebastianelli, S.: Comparison of methodologies for flood rainfall thresholds estimation., Natural Hazards, 75, 909-934, https://doi.org/10.1007/s11069-014-1357-3, 2015.

Nabian, M. A. and Meidani, H.: Uncertainty quantification and pca-based model reduction for parallel monte carlo analysis of 580 infrastructure system reliability., In 96th Annual Meeting of the Transportation Research Board, Washington DC, 2017.

Olson, D. L. and Delen, D.: Advanced data mining techniques. Springer Science \& Business Media, 2008.

Park, S. and Kang, B.: Differentiating Scheme for the Storm Warning Criteria Considering the Regional Disaster Prevention Capacity., Journal of the Korean Society of Hazard Mitigation, 14, 67-76, https://doi.org/10.9798/KOSHAM.2014.14.5.67, 2014.

585 Piciullo, L., Siano, I. and Calvello, M.: Calibration of rainfall thresholds for landslide early warning purposes: applying the EDuMaP method to the system deployed in Campania region (Italy)., In Proceedings of the International Symposium on Landslides, 1621-1629, https://doi.org/10.1201/b21520-201, 2016.

Powers, D. M.: Evaluation from precision, recall and F-measure to ROC, informedness, markedness and correlation., Journal of Machine Learning Technologies, 2, 37-63, 2011.

590 Rossi, M., Luciani, S., Valigi, D., Kirschbaum, D., Brunetti, M. T., Peruccacci, S. and Guzzetti, F.: Statistical approaches for the definition of landslide rainfall thresholds and their uncertainty using rain gauge and satellite data., Geomorphology, 285, 16-27, https://doi.org/10.1016/j.geomorph.2017.02.001, 2017.

Sairam, N., Schröter, K., Rözer, V., Merz, B., and Kreibich, H.: Hierarchical Bayesian approach for modeling spatiotemporal variability in flood damage processes., Water Resources Research, 55, 8223-8237, https://doi.org/10.1029/2019WR025068, 5952019.

Saito, T. and Rehmsmeier, M.: The Precision-Recall Plot Is More Informative than the ROC Plot When Evaluating Binary Classifiers on Imbalanced Datasets., PLoS ONE 10(3): e0118432. https://doi.org/10.1371/journal.pone.0118432, 2015

Sasaki, Y.: The Truth of the F-Measure., 2007. 
https://doi.org/10.5194/nhess-2020-295

Preprint. Discussion started: 9 October 2020

(c) Author(s) 2020. CC BY 4.0 License.

Sieg, T., Vogel, K., Merz, B., and Kreibich, H.: Tree-based flood damage modeling of companies: Damage processes and

600 model performance., Water Resources Research, 53, 6050-6068, https://doi.org/10.1002/2017WR020784, 2017.

Song, Y. S., Lim, C. H., Joo, J. G. and Park, M. J.: A study on heavy rain forecast evaluation and improvement method., Journal of the Korean Society of Hazard Mitigation, 16, 113-121, https://doi.org/10.9798/KOSHAM.2016.16.2.113, 2016.

Wilby, R. L. and Keenan, R.: Adapting to flood risk under climate change., Progress in physical geography, 36, 348-378, https://doi.org/10.1177/0309133312438908, 2012.

605 Wold, S., Esbensen, K. and Geladi, P.: Principal component analysis., Chemometrics and intelligent laboratory systems, 2, 37 52, https://doi.org/10.1016/0169-7439(87)80084-9, 1987.

Yang, T. H., Hwang, G. D., Tsai, C. C. and Ho, J. Y.: Using rainfall thresholds and ensemble precipitation forecasts to issue and improve urban inundation alerts., Hydrology and Earth System Sciences, 20, 4731-4745, https://doi.org/10.5194/hess-204731-2016, 2016.

610 Zhai, X., Guo, L., Liu, R. and Zhang, Y.: Rainfall threshold determination for flash flood warning in mountainous catchments with consideration of antecedent soil moisture and rainfall pattern., Natural Hazards, 94, 605-625, https://doi.org/10.1007/s11069-018-3404-y, 2018. 
https://doi.org/10.5194/nhess-2020-295

Preprint. Discussion started: 9 October 2020

(c) Author(s) 2020. CC BY 4.0 License.
Natural Hazards and Earth System

Sciences

Discussions

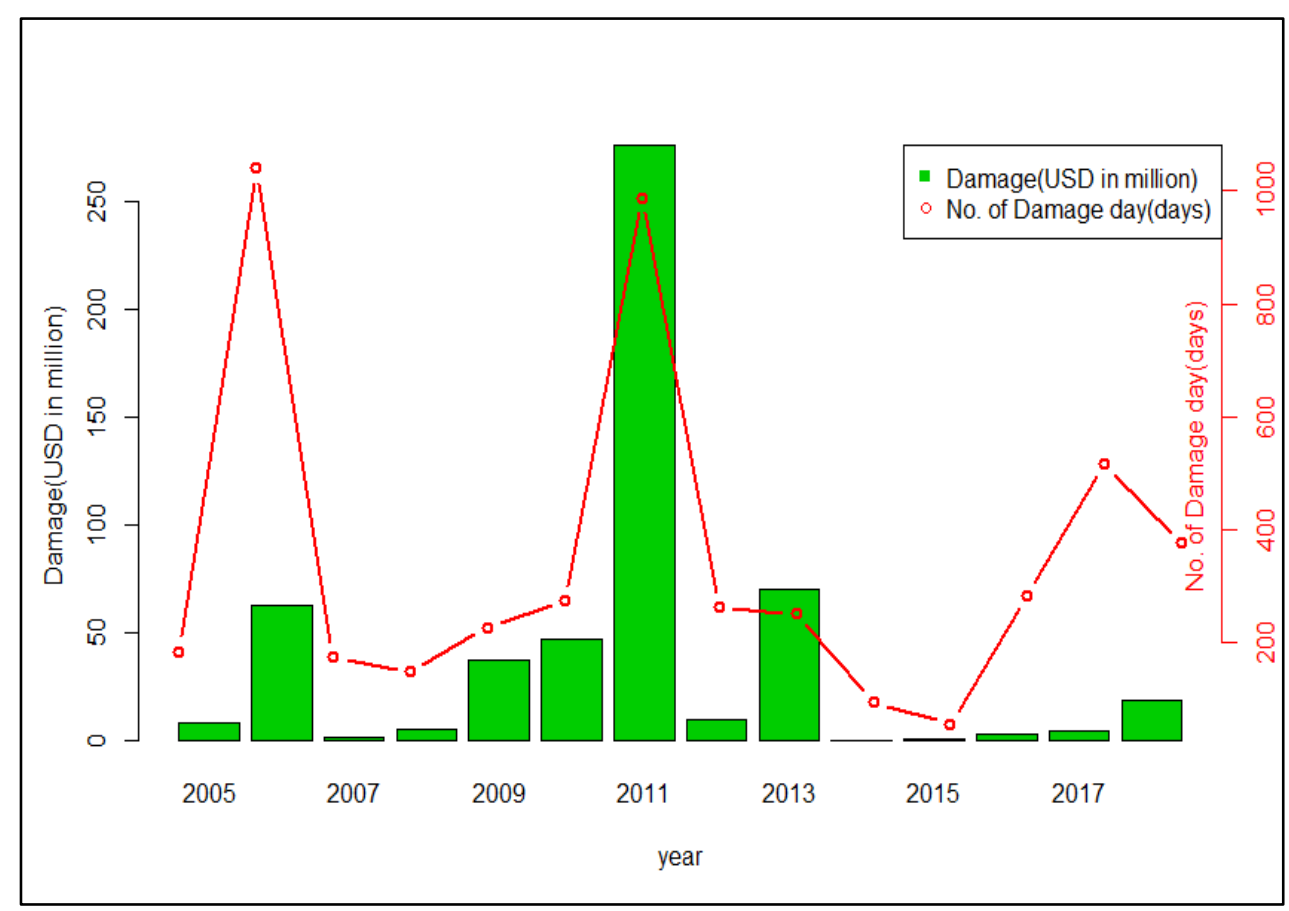

Figure 1: Heavy rain damage and no. of damage days

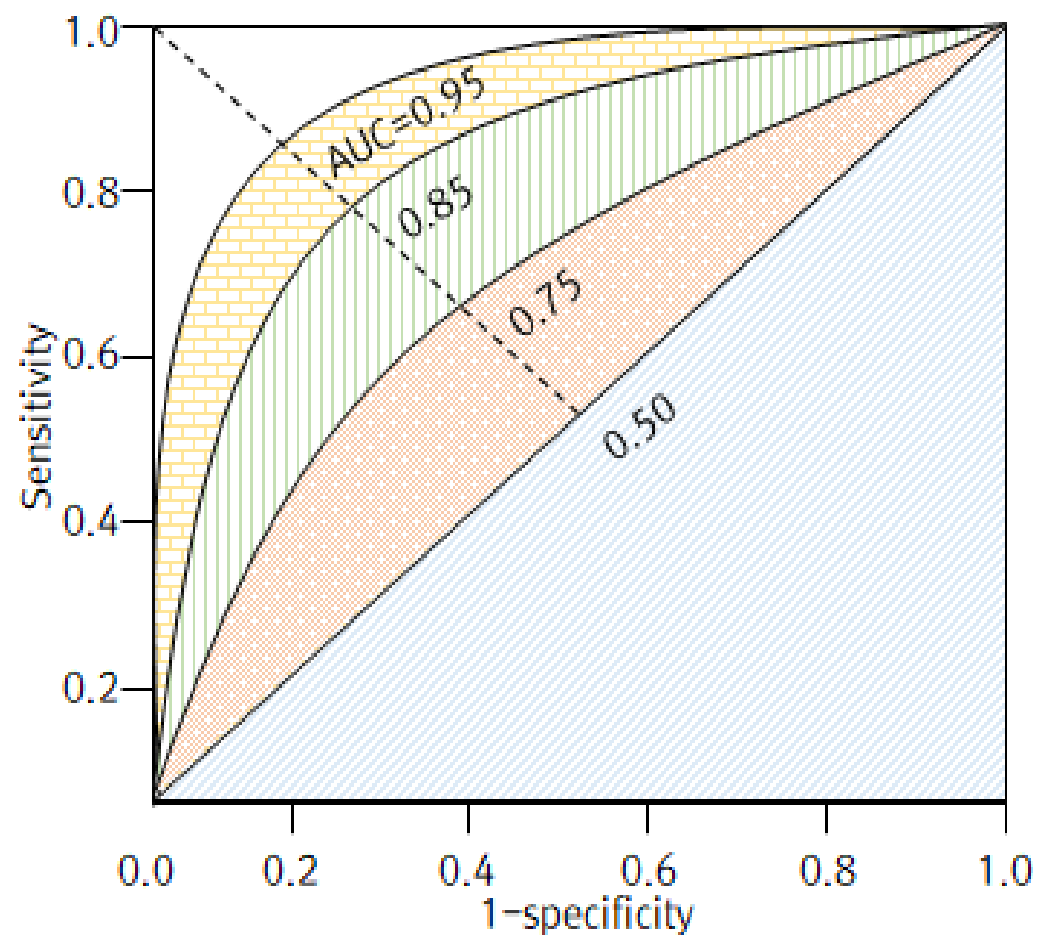

Figure 2: Concept of ROC curve and AUC(Choi, 2018) 
https://doi.org/10.5194/nhess-2020-295

Preprint. Discussion started: 9 October 2020

(c) Author(s) 2020. CC BY 4.0 License.
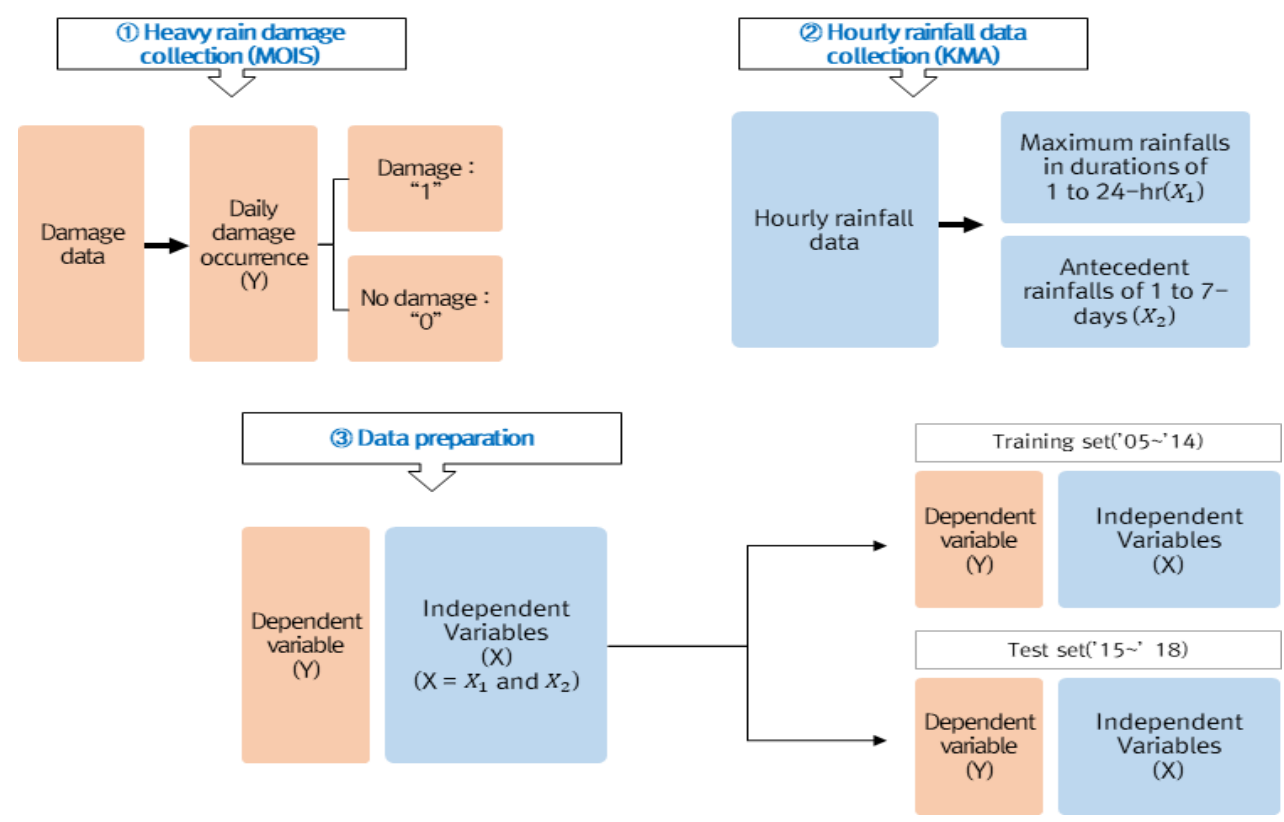

Figure 3: Establishment of dependent and independent variables for HD-TRC

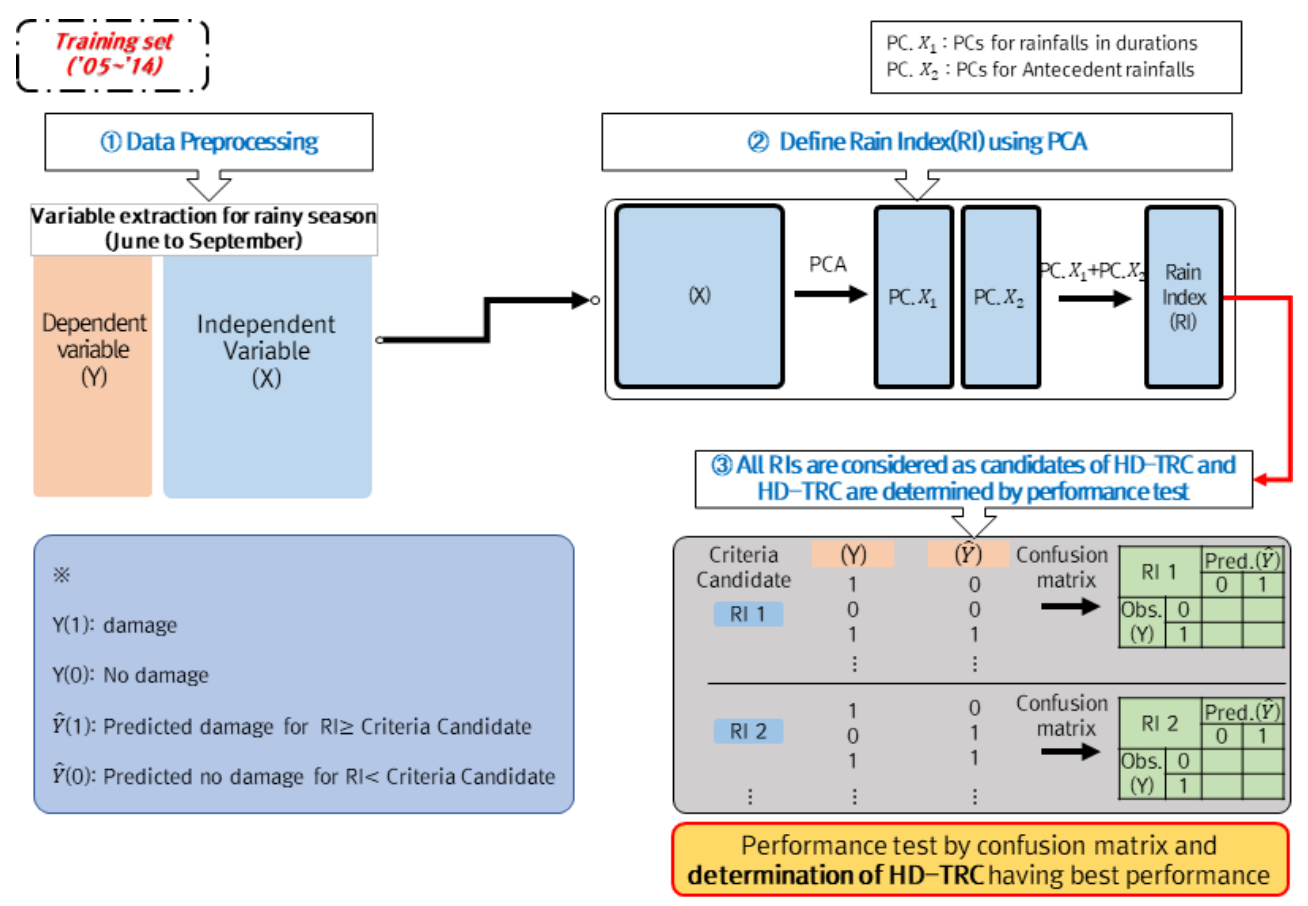

Figure 4: Determination of the best HD-TRC by performance test for training set 
https://doi.org/10.5194/nhess-2020-295

Preprint. Discussion started: 9 October 2020

(c) Author(s) 2020. CC BY 4.0 License.
Natural Hazards and Earth System Sciences

Discussions

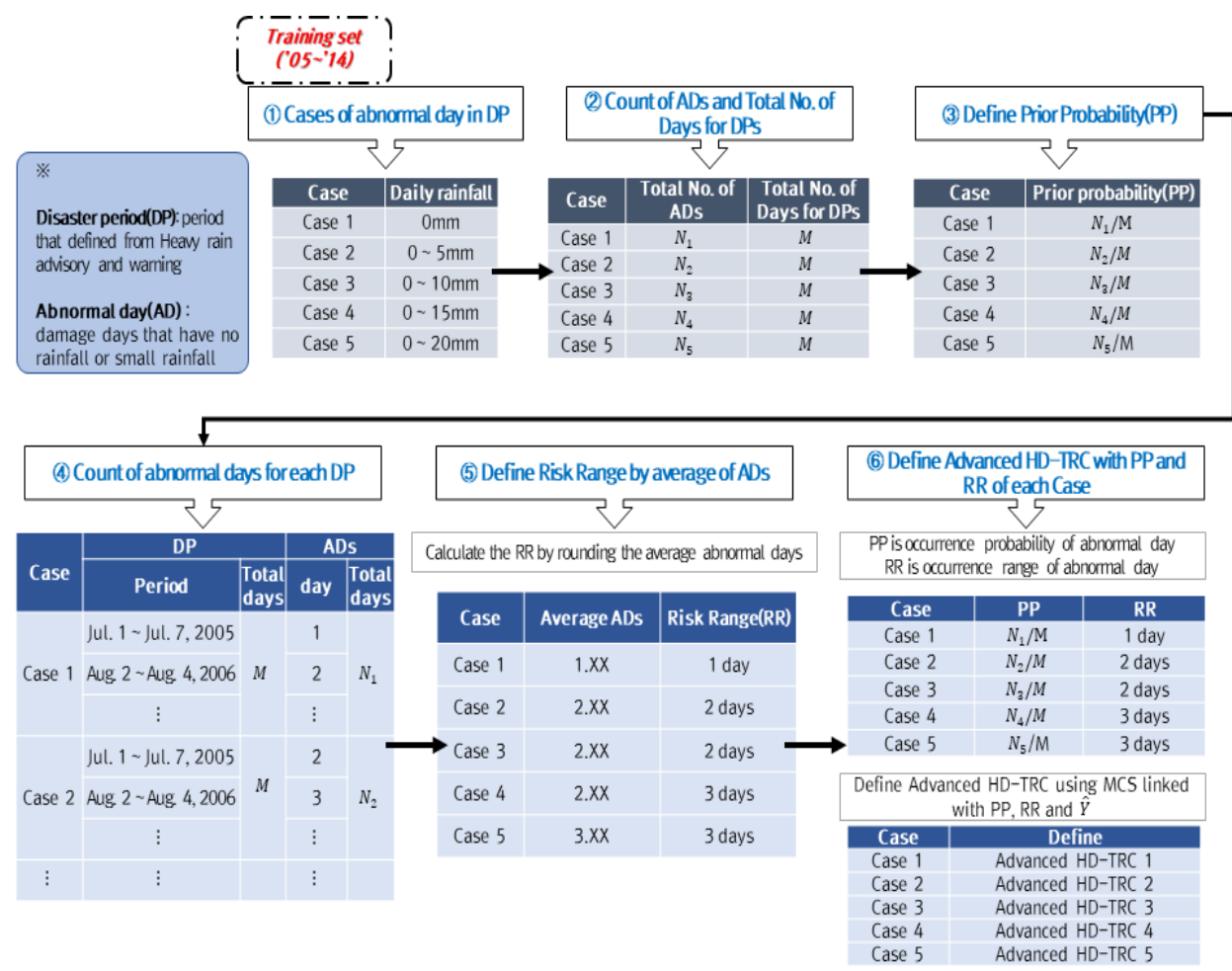

Figure 5: Process of Advanced HD-TRC using occurrence probability and range of abnormal day

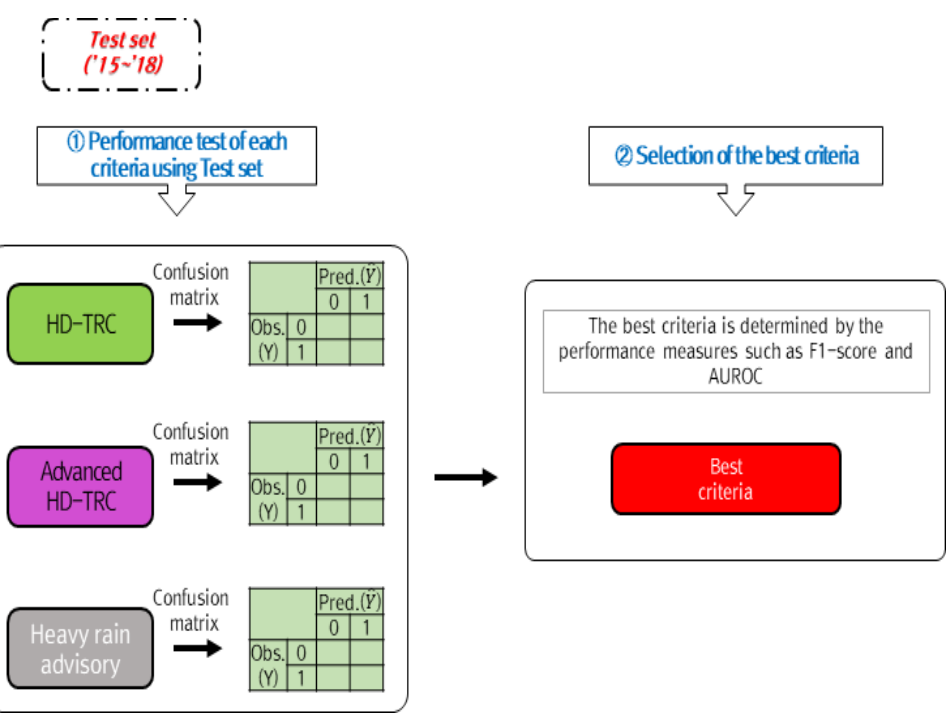

Figure 6: Selection of the best criteria after comparison of performance 
https://doi.org/10.5194/nhess-2020-295

Preprint. Discussion started: 9 October 2020

(c) Author(s) 2020. CC BY 4.0 License.

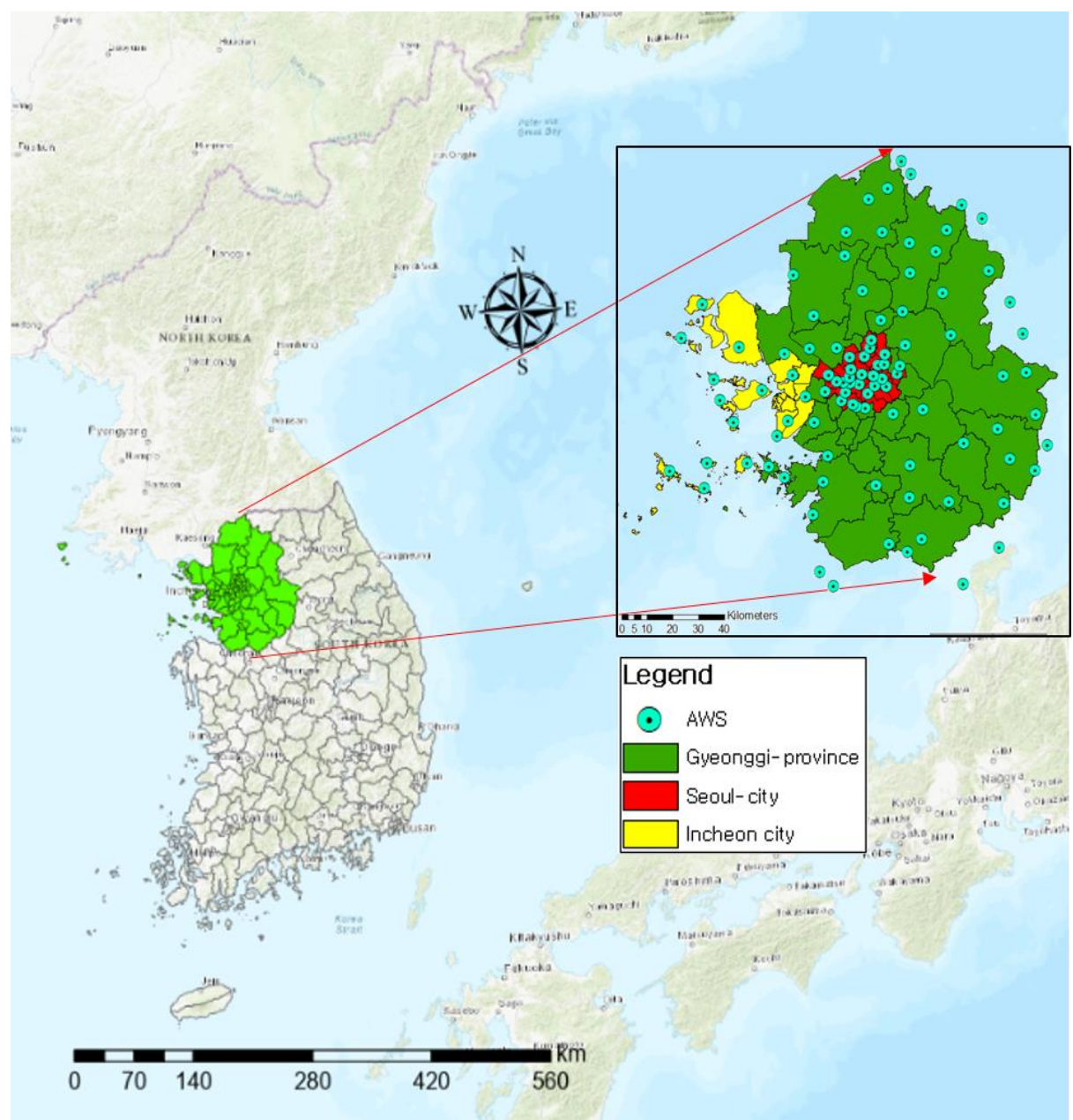

Figure 7: Study Region in the Korean peninsular 


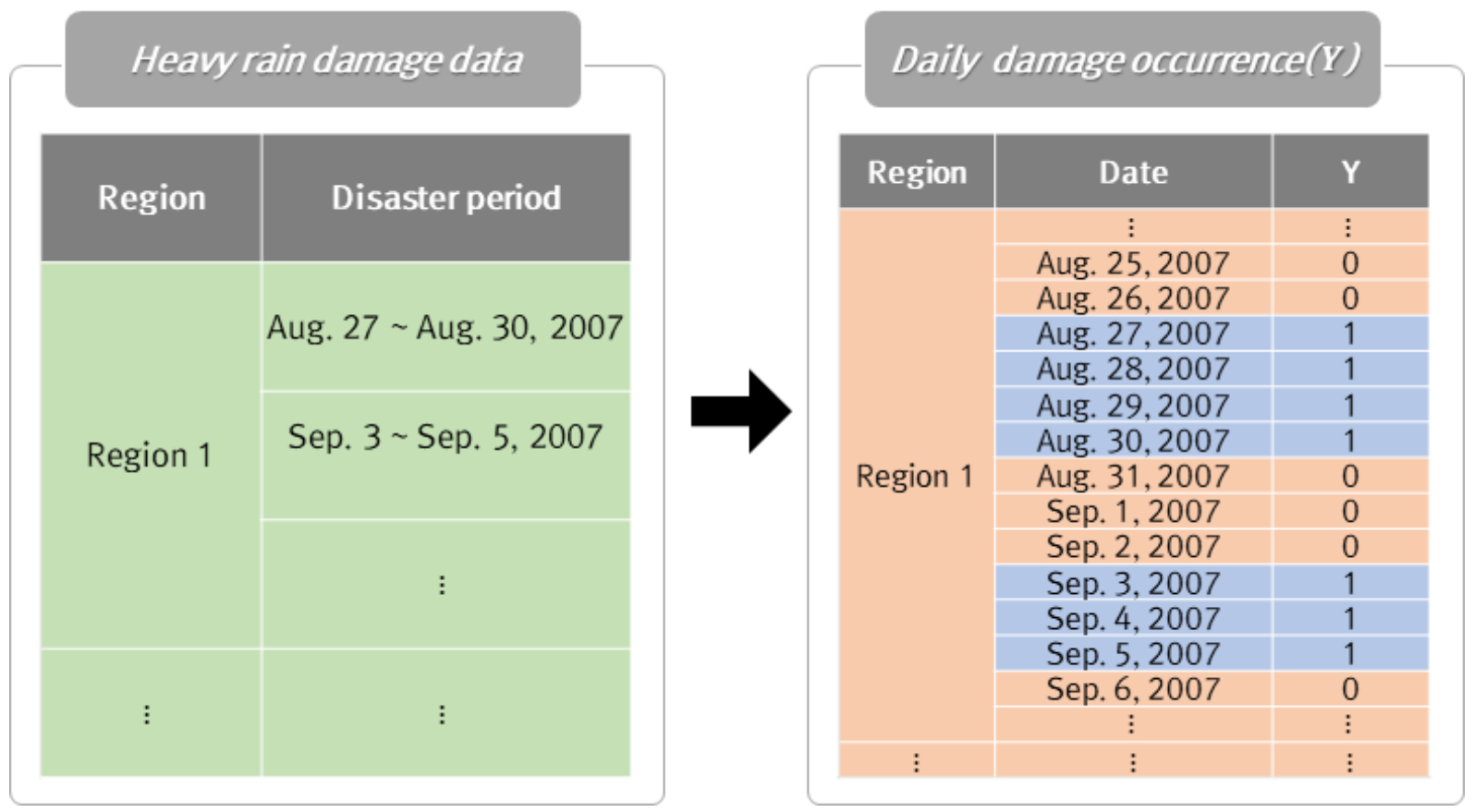

Figure 8 Concept of daily damage occurrence to obtain dependent variable

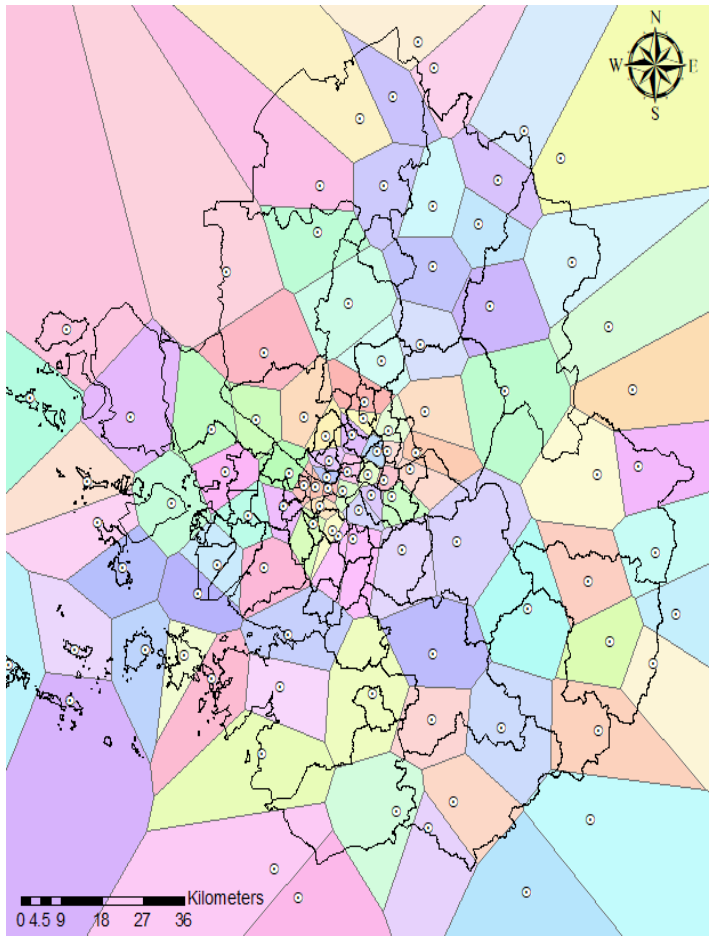

Figure 9: Thiessen polygons for the study region 
https://doi.org/10.5194/nhess-2020-295

Preprint. Discussion started: 9 October 2020

(c) Author(s) 2020. CC BY 4.0 License.
Natural Hazards and Earth System

Sciences

Discussions

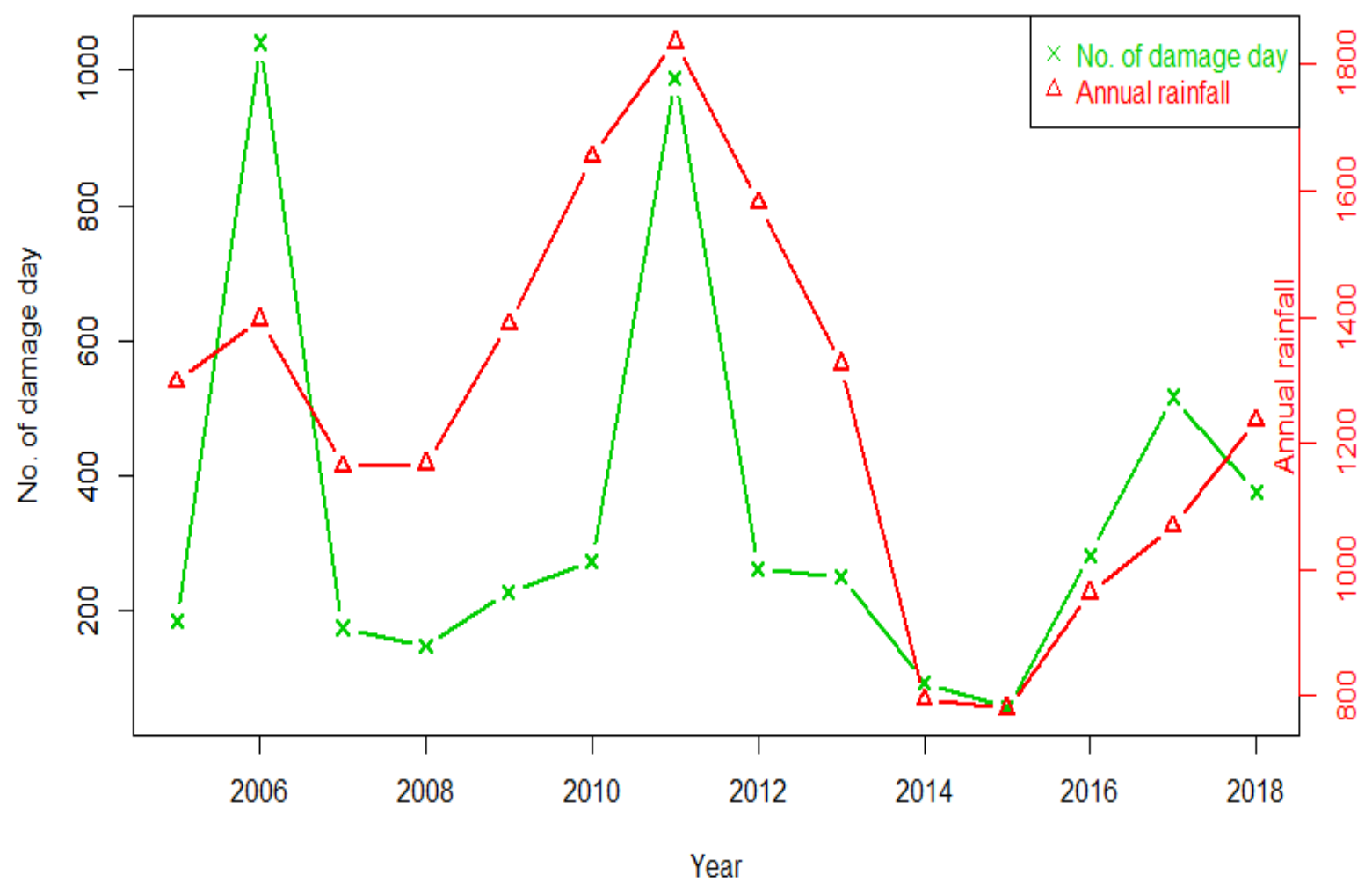

Figure 10: Plots for number of damage day and annual rainfall

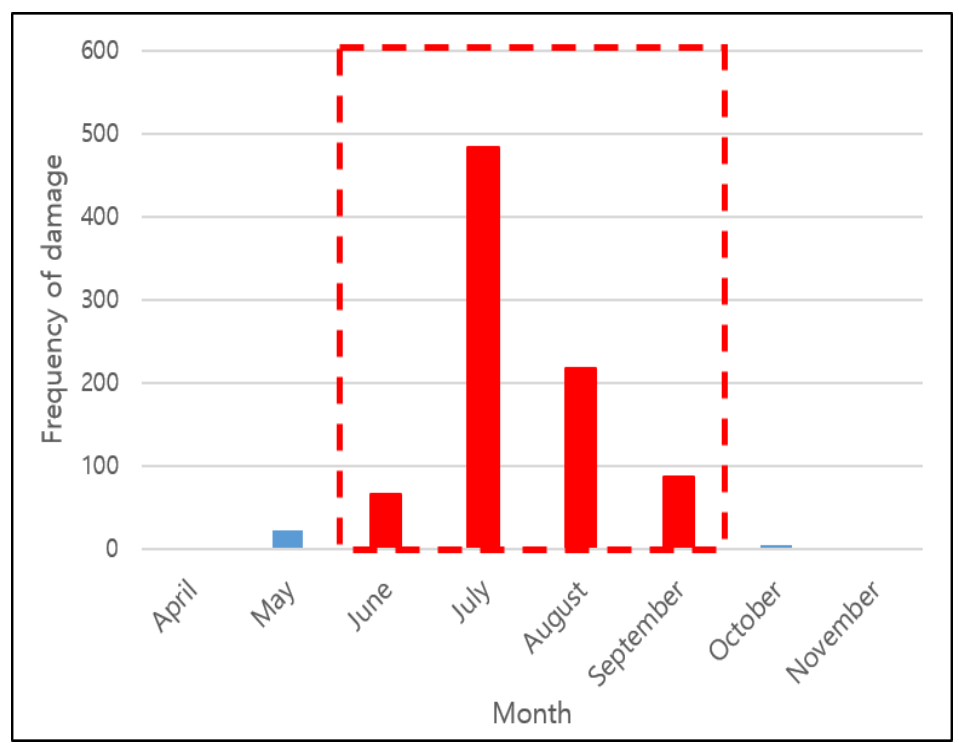

Figure 11: Frequency of heavy rain damage in each month 
https://doi.org/10.5194/nhess-2020-295

Preprint. Discussion started: 9 October 2020

(c) Author(s) 2020. CC BY 4.0 License.

(c) (1)

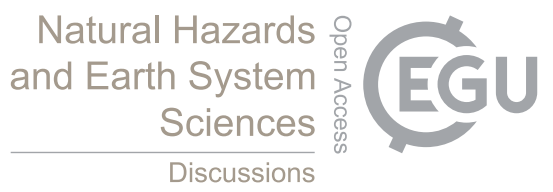

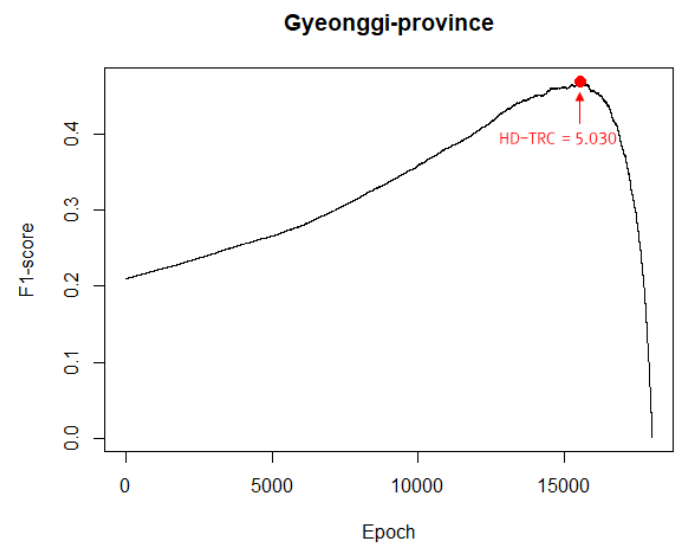
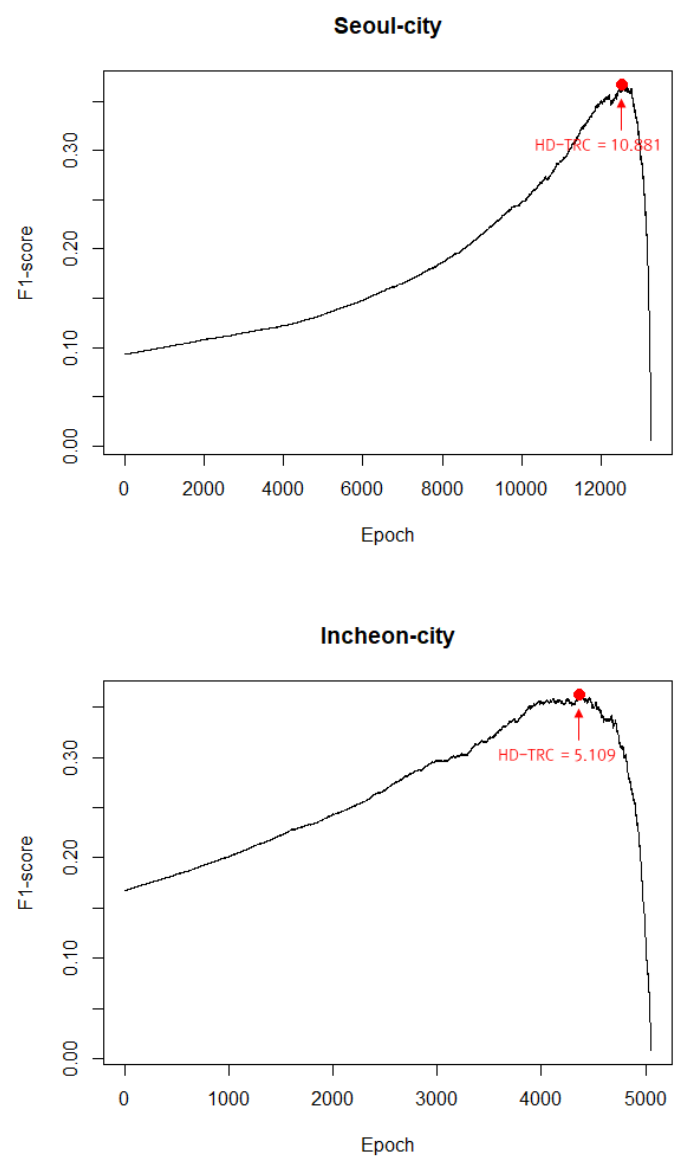

Figure 12: Performance evaluation and determination of HD-TRC by F1-score for each region 
https://doi.org/10.5194/nhess-2020-295

Preprint. Discussion started: 9 October 2020

(c) Author(s) 2020. CC BY 4.0 License.
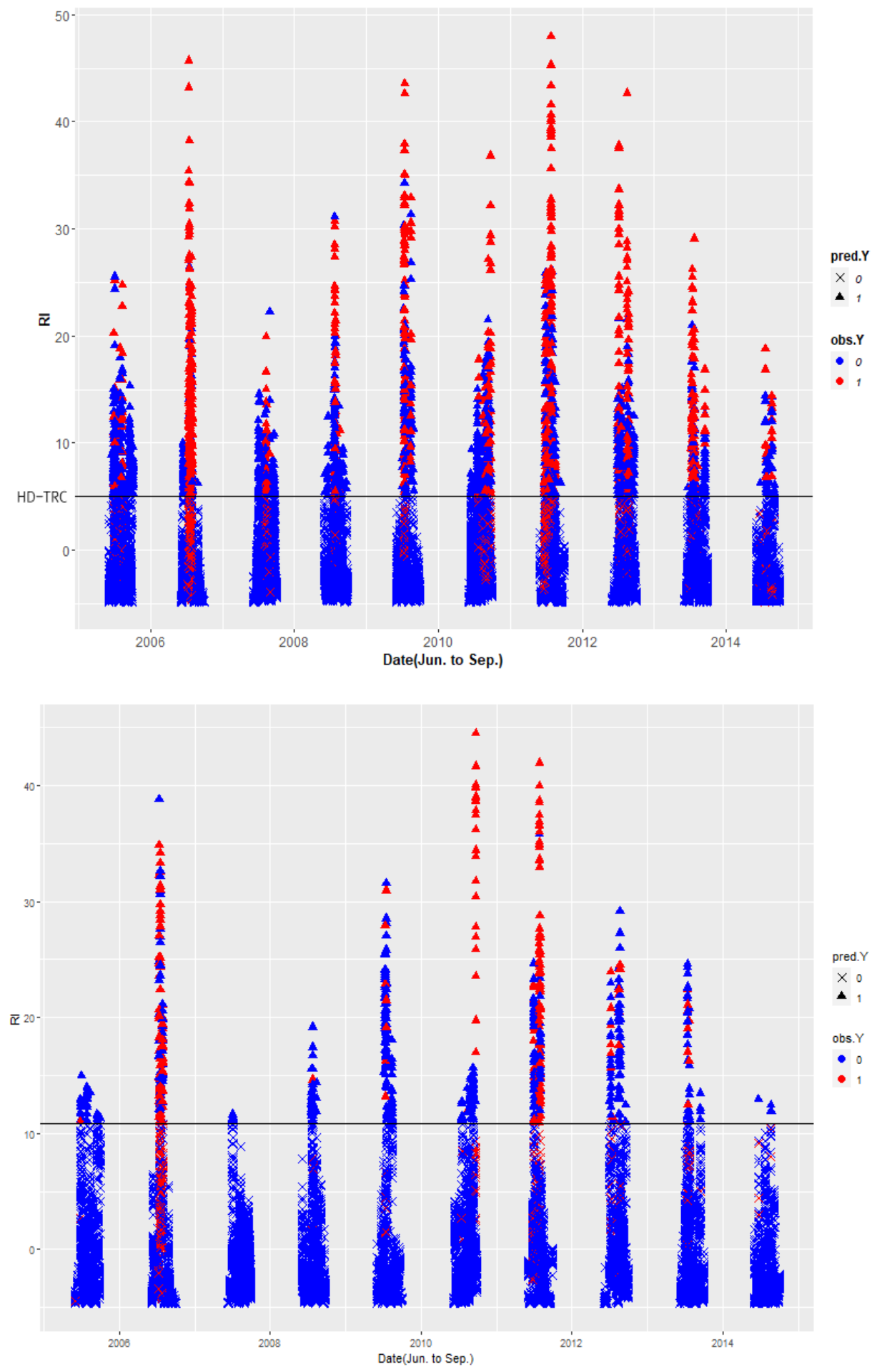
https://doi.org/10.5194/nhess-2020-295

Preprint. Discussion started: 9 October 2020

(c) Author(s) 2020. CC BY 4.0 License.

\section{Natural Hazards o

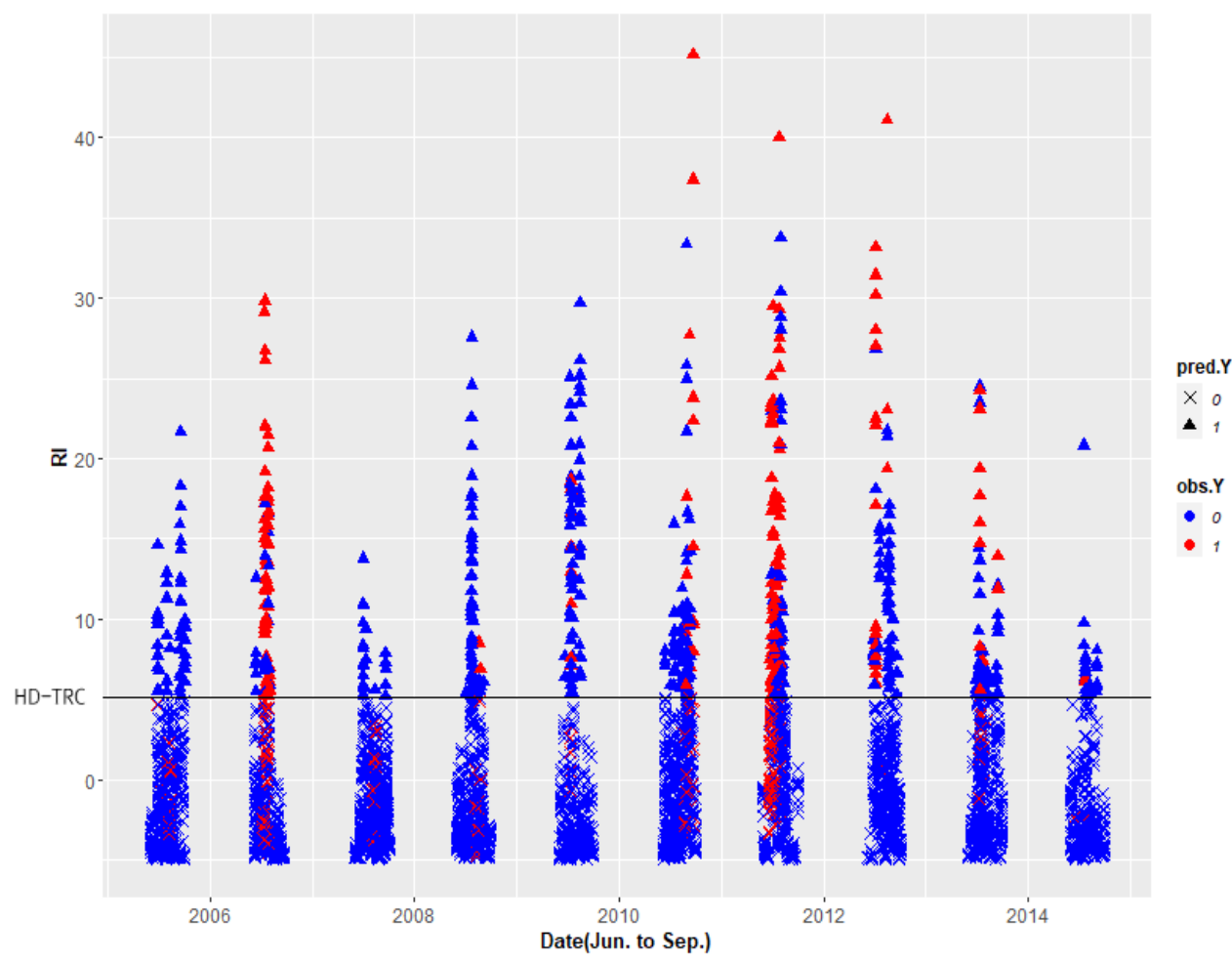

Figure 13: Classification based on RIs from training set and the determined HD-TRC for each region : red triangle-TP, blue triangle-FP, red cross-FN, blue cross-TN (see Table 3) 
https://doi.org/10.5194/nhess-2020-295

Preprint. Discussion started: 9 October 2020

(c) Author(s) 2020. CC BY 4.0 License.

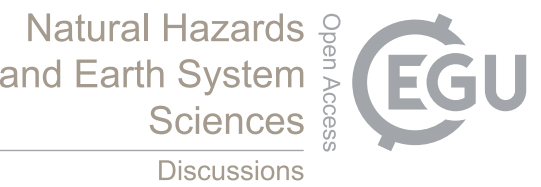

1. $\mathrm{PP}=0.32(0.3199)$

2. $R R=2$ days

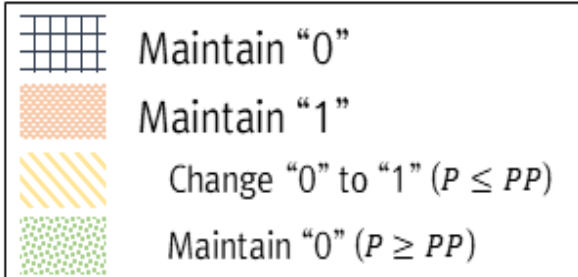

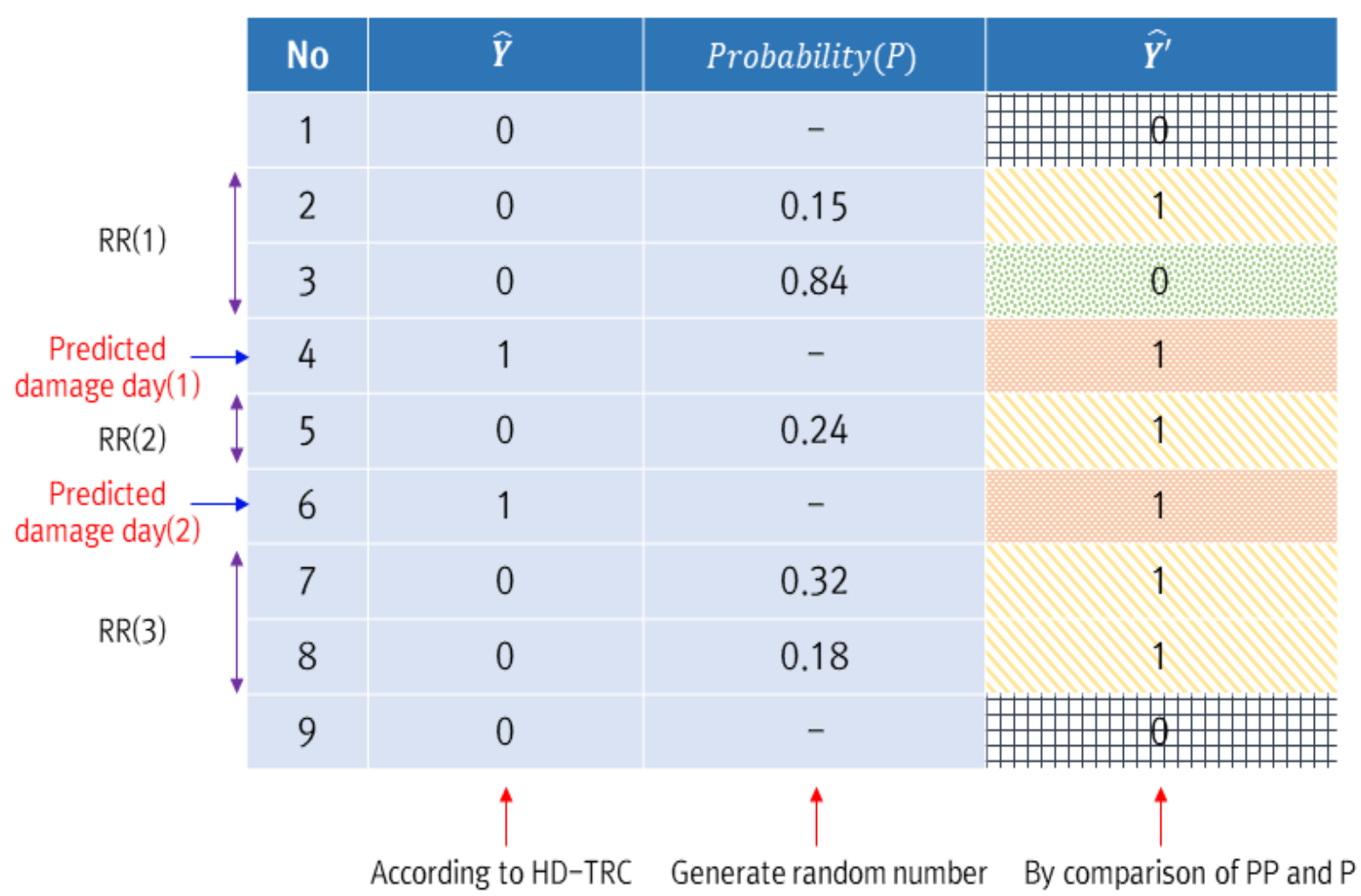

Figure 14: An analysis example of Advanced HD-TRC using MCS with PP and RR for case 2 in Table 11 
https://doi.org/10.5194/nhess-2020-295

Preprint. Discussion started: 9 October 2020

(c) Author(s) 2020. CC BY 4.0 License.

Table 1: Heavy rain warning criteria used in each country

\begin{tabular}{|c|c|c|c|c|}
\hline Country & \multicolumn{4}{|c|}{ Warning criteria for heavy rain } \\
\hline \multirow{4}{*}{ Japan } & \multicolumn{2}{|c|}{ Heavy Rain Advisory (HRA) } & \multicolumn{2}{|c|}{ Heavy Rain Warning (HRW) } \\
\hline & \multirow{2}{*}{\multicolumn{2}{|c|}{$\begin{array}{c}20 \mathrm{~mm} / \mathrm{hr} \sim 50 \mathrm{~mm} / \mathrm{hr} \text { (Soil Water Index 95 184) } \\
\text { or } 60 \mathrm{~mm} / \mathrm{hr} \sim 80 \mathrm{~mm} / 3 \mathrm{hr} \text { (Soil Water Index }\end{array}$}} & \multicolumn{2}{|c|}{$40 \mathrm{~mm} / \mathrm{hr} \sim 80 \mathrm{~mm} / \mathrm{hr}$ (Soil Water Index 80 156) } \\
\hline & & & \multicolumn{2}{|c|}{ or $70 \mathrm{~mm} / 3 \mathrm{hr} \sim 120 \mathrm{~mm} / 3 \mathrm{hr}$ (Soil Water Index } \\
\hline & \multicolumn{2}{|c|}{ 95 184) } & \multicolumn{2}{|c|}{$80 \sim 156)$} \\
\hline \multirow{2}{*}{ Hongkong } & Amber & & ed & Black \\
\hline & $>30 \mathrm{~mm} / 1 \mathrm{hr}$ & $>50 n$ & $\mathrm{~m} / 1 \mathrm{hr}$ & $>70 \mathrm{~mm} / 1 \mathrm{hr}$ \\
\hline \multirow{3}{*}{ Canada } & \multicolumn{4}{|c|}{ Heavy Rain Warning } \\
\hline & Prairie and Northern & Dry sets of $\mathrm{Br}$ & itish Columbia & Atlantic Region \\
\hline & $>50 \mathrm{~mm} / 1 \mathrm{hr}$ & $>15 n$ & $\mathrm{Im} / 1 \mathrm{hr}$ & $>25 \mathrm{~mm} / 1 \mathrm{hr}$ \\
\hline \multirow{2}{*}{ Korea } & \multicolumn{2}{|c|}{ Heavy Rain Advisory } & \multicolumn{2}{|c|}{ Heavy Rain Warning } \\
\hline & \multicolumn{2}{|c|}{$>60 \mathrm{~mm} / 3 \mathrm{hr}$ or $>110 \mathrm{~mm} / 12 \mathrm{hr}$} & \multicolumn{2}{|c|}{$>90 \mathrm{~mm} / 3 \mathrm{hr}$ or $>180 \mathrm{~mm} / 12 \mathrm{hr}$} \\
\hline
\end{tabular}


Table 2: An example of SYND published by MOIS, Korea (heavy rain damage of Nowon-district in Seoul-city)

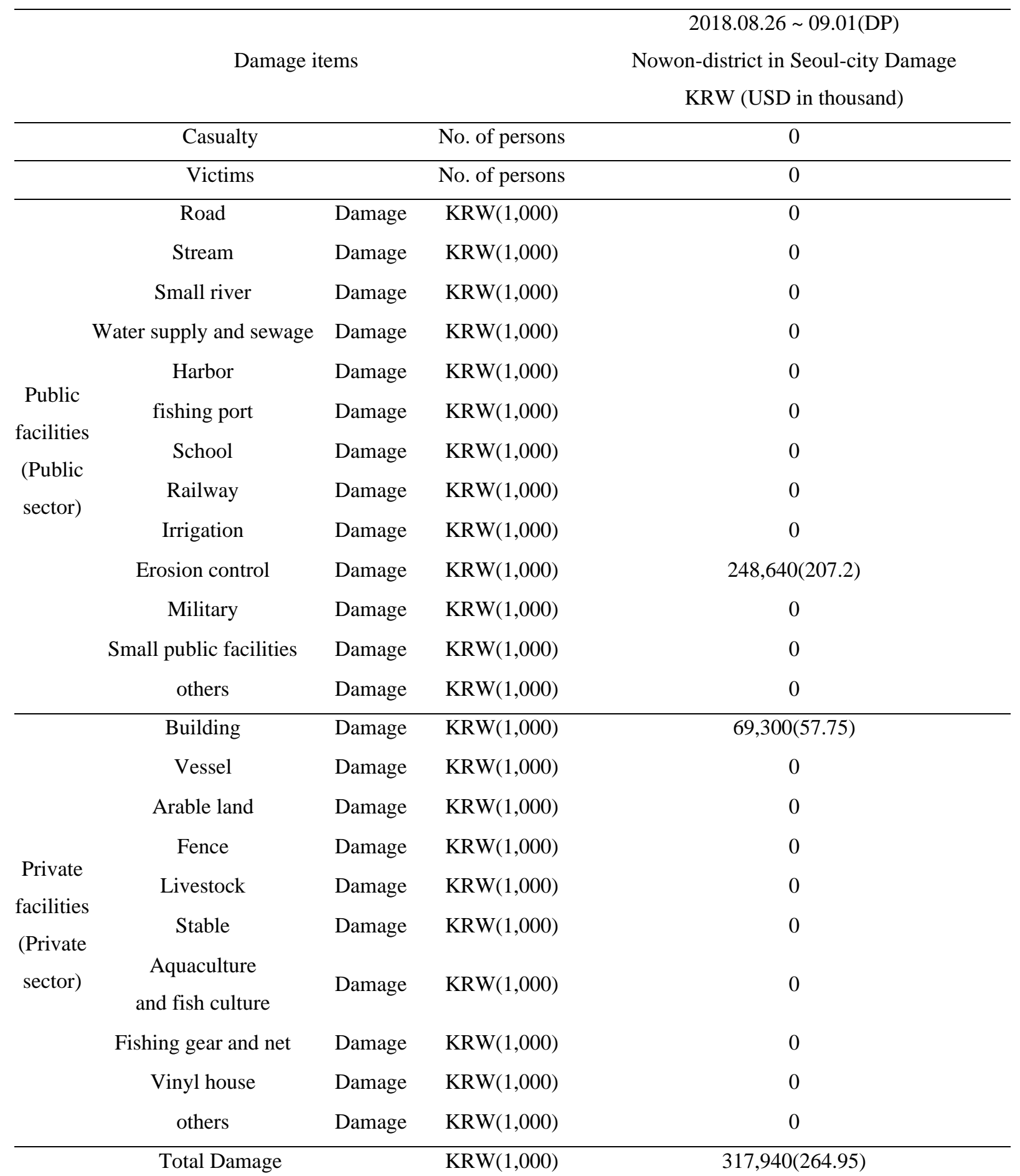


Table 3: Confusion matrix

\begin{tabular}{cl|cc}
\hline \multicolumn{2}{c|}{ Condition } & \multicolumn{2}{c}{$\operatorname{Predicted}(\widehat{\boldsymbol{Y}})$} \\
& & 0 & 1 \\
\hline Observed & 0 & TN & FP \\
$(\boldsymbol{Y})$ & 1 & FN & TP \\
\hline
\end{tabular}

Table 4: Performance evaluation indicators(Powers, 2011)

\begin{tabular}{cc}
\hline Evaluation indicators & Equation \\
\hline Accuracy & $\frac{T P+T N}{T P+T N+P F+F N}$ \\
Error Rate & $\frac{F P+F N}{T P+T N+P F+F N}$ \\
Sensitivity(recall) & $\frac{T P}{T P+F N}$ \\
Precision & $\frac{T P}{T P+F P}$ \\
Specificity & $\frac{T N}{T N+F P}$ \\
\hline
\end{tabular}

Table 5: Dependent and independent variables for the determination of HD-TRC

\begin{tabular}{cc}
\hline Variable & Description \\
\hline Dependent variable & Daily damage occurrence $(Y)$ \\
\hline Independent variable & Maximum rainfalls in durations of 1 to $24-\mathrm{hr}\left(X_{1}\right)$ \\
& Antecedent rainfalls of 1 to $7-\operatorname{day}\left(X_{2}\right)$ \\
\hline
\end{tabular}

Table 6: Frequency of Heavy rain Damage for the Province and Cities

\begin{tabular}{ccc}
\hline Province and city & $\begin{array}{c}\text { Frequency of heavy rain } \\
\text { damage } \\
\text { for each region }\end{array}$ & $\begin{array}{c}\text { Average frequency of heavy rain damage } \\
\text { for each administrative district }\end{array}$ \\
\hline Gyeonggi-province & 616 & 19.87 (for 31 districts) \\
Seoul-city & 150 & 6 (for 25 districts) \\
Incheon-city & 121 & 12.1 (for 10 districts) \\
\hline
\end{tabular}


https://doi.org/10.5194/nhess-2020-295

Preprint. Discussion started: 9 October 2020

(c) Author(s) 2020. CC BY 4.0 License.

Table 7: No. of damage days(1) and no damage days $(0)$ for whole years and rainy season

\begin{tabular}{|c|c|c|c|c|c|c|}
\hline \multirow{2}{*}{$\begin{array}{c}\text { For whole } \\
\text { years }\end{array}$} & \multicolumn{2}{|c|}{$\begin{array}{l}\text { No. of damage } \& \\
\text { no damage days }\end{array}$} & & \multirow{2}{*}{$\begin{array}{c}\text { For rainy } \\
\text { season }\end{array}$} & \multicolumn{2}{|c|}{$\begin{array}{l}\text { No. of damage } \& \\
\text { no damage days }\end{array}$} \\
\hline & 1 & 0 & & & 1 & 0 \\
\hline $\begin{array}{l}\text { Gyeonggi- } \\
\text { province }\end{array}$ & 2,354 & 110,858 & $\Rightarrow$ & $\begin{array}{l}\text { Gyeonggi- } \\
\text { province }\end{array}$ & 2,115 & 15,940 \\
\hline Seoul-city & 740 & 90,560 & & Seoul-city & 648 & 12,647 \\
\hline Incheon-city & 551 & 35,970 & & Incheon-city & 463 & 4,606 \\
\hline
\end{tabular}

Table 8: Cumulative variance for each rainfall variable of $X_{1}$ and $X_{2}$ in the region

\begin{tabular}{cccc}
\hline Rainfall variable & Gyeonggi-province & Seoul-city & Incheon-city \\
\hline$P C . X_{1}$ & 0.8009 & 0.8001 & 0.8026 \\
\hline$P C . X_{2}$ & 0.9702 & 0.9708 & 0.9719
\end{tabular}

Table 9: Determined HD-TRC and classification performance evaluation for each region

\begin{tabular}{ccccccc}
\hline Region & HD-TRC & Sensitivity & Specificity & Precision & AUC & F1-score \\
\hline $\begin{array}{c}\text { Gyeonggi- } \\
\text { province }\end{array}$ & 5.030 & 0.503 & 0.914 & 0.438 & 0.709 & 0.468 \\
Seoul-city & 10.881 & 0.387 & 0.963 & 0.347 & 0.675 & 0.366 \\
Incheon-city & 5.109 & 0.449 & 0.896 & 0.303 & 0.673 & 0.362 \\
\hline
\end{tabular}


https://doi.org/10.5194/nhess-2020-295

Preprint. Discussion started: 9 October 2020

(c) Author(s) 2020. CC BY 4.0 License.

(c) (i)

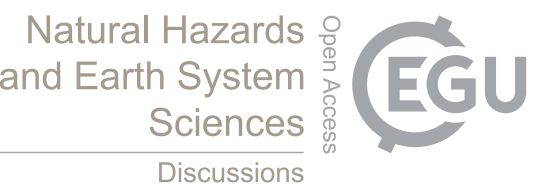

680 Table 10: Confusion matrix of HD-TRC for each region

\begin{tabular}{|c|c|c|c|}
\hline \multirow{2}{*}{$\begin{array}{l}\text { Gyeonggi- } \\
\text { province }\end{array}$} & & \multicolumn{2}{|c|}{ Predicted $(\widehat{Y})$} \\
\hline & & 0 & 1 \\
\hline \multirow{4}{*}{ Observed $(Y)$} & 0 & 14574 & 1366 \\
\hline & & $(\mathrm{TN})$ & $(\mathrm{FP})$ \\
\hline & & 1051 & 1064 \\
\hline & 1 & $(\mathrm{FN})$ & (TP) \\
\hline
\end{tabular}

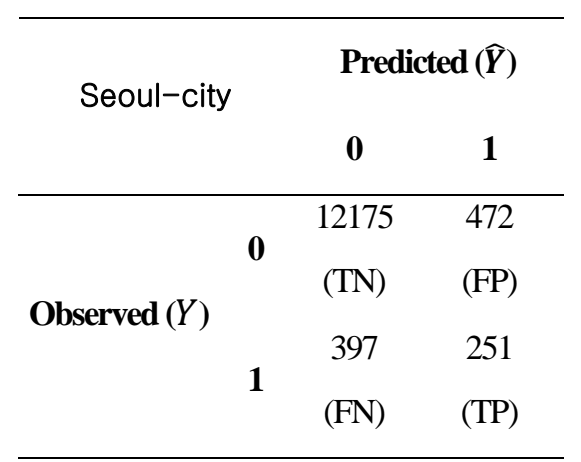

\begin{tabular}{|c|c|c|}
\hline \multirow{2}{*}{ Incheon-city } & \multicolumn{2}{|c|}{ Predicted $(\widehat{Y})$} \\
\hline & 0 & 1 \\
\hline \multirow{4}{*}{ Observed $(Y)$} & 4128 & 478 \\
\hline & & (FP) \\
\hline & 255 & 208 \\
\hline & $(\mathrm{FN})$ & (TP) \\
\hline
\end{tabular}

Table 11: Calculations of PP and RR for each case

\begin{tabular}{cccccc}
\hline Case & $\begin{array}{c}\text { Daily rainfall } \\
\text { during DP }\end{array}$ & $\begin{array}{c}\text { Total no. of days for } \\
\text { DPs (M) }\end{array}$ & $\begin{array}{c}\text { Total no. of ADs } \\
\text { (N) }\end{array}$ & $\begin{array}{c}\text { Prior Probability } \\
\text { (PP) (N/M) }\end{array}$ & Risk Range (RR) \\
\hline Case 1 & $0 \mathrm{~mm}$ & 3,645 & 411 & 0.1128 & 1 day \\
Case 2 & $5 \mathrm{~mm}$ & 3,645 & 1,166 & 0.3199 & 2 days \\
Case 3 & $10 \mathrm{~mm}$ & 3,645 & 1,435 & 0.3936 & 2 days \\
Case 4 & $15 \mathrm{~mm}$ & 3,645 & 1,656 & 0.4543 & 2 days \\
Case 5 & $20 \mathrm{~mm}$ & 3,645 & 1,837 & 0.5040 & 3 days \\
\hline
\end{tabular}


https://doi.org/10.5194/nhess-2020-295

Preprint. Discussion started: 9 October 2020

(C) Author(s) 2020. CC BY 4.0 License.

(c) (1)

Table 12: Result of performance evaluation in Gyeonggi-province

\begin{tabular}{cccccc}
\hline Criteria & Sensitivity & Specificity & Precision & F1-score & AUC \\
\hline HRA of KMA & $6.26 \%$ & $99.94 \%$ & $66.67 \%$ & $11.44 \%$ & $53.10 \%$ \\
HD-TRC & $28.88 \%$ & $99.29 \%$ & $43.17 \%$ & $34.61 \%$ & $64.08 \%$ \\
$\begin{array}{c}\text { Advanced HD-TRC 1 } \\
\text { (Case1) }\end{array}$ & $32.49 \%$ & $99.16 \%$ & $42.06 \%$ & $36.67 \%$ & $65.77 \%$ \\
$\begin{array}{c}\text { Advanced HD-TRC 2 } \\
\text { (Case2) }\end{array}$ & $41.64 \%$ & $98.41 \%$ & $32.86 \%$ & $36.73 \%$ & $70.02 \%$ \\
Advanced HD-TRC 3 & & & & \\
(Case3) & $45.61 \%$ & $98.16 \%$ & $31.66 \%$ & $37.36 \%$ & $71.88 \%$ \\
Advanced HD-TRC 4 & & & & \\
(Case4) & $48.74 \%$ & $97.98 \%$ & $31.06 \%$ & $37.94 \%$ & $73.36 \%$ \\
Advanced HD-TRC 5 & & & & \\
(Case5) & $57.04 \%$ & $97.28 \%$ & $28.16 \%$ & $37.71 \%$ & $77.16 \%$ \\
\hline
\end{tabular}


https://doi.org/10.5194/nhess-2020-295

Preprint. Discussion started: 9 October 2020

(C) Author(s) 2020. CC BY 4.0 License.

(c) (1)

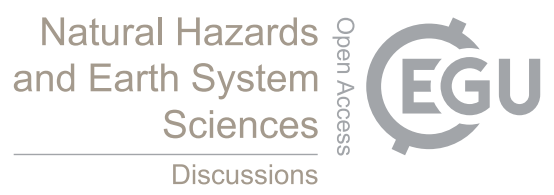

Table 13: Result of performance evaluation in Seoul-city

\begin{tabular}{|c|c|c|c|c|c|}
\hline Criteria & Sensitivity & Specificity & Precision & F1-score & AUC \\
\hline HRA of KMA & $14.21 \%$ & $99.84 \%$ & $32.94 \%$ & $19.86 \%$ & $57.03 \%$ \\
\hline HD-TRC & $19.80 \%$ & $99.79 \%$ & $33.62 \%$ & $24.92 \%$ & $59.79 \%$ \\
\hline $\begin{array}{l}\text { Advanced HD-TRC } 1 \\
\text { (Case1) }\end{array}$ & $21.83 \%$ & $99.75 \%$ & $32.33 \%$ & $26.06 \%$ & $60.79 \%$ \\
\hline $\begin{array}{c}\text { Advanced HD-TRC } 2 \\
\text { (Case2) }\end{array}$ & $30.46 \%$ & $99.49 \%$ & $24.59 \%$ & $27.21 \%$ & $64.98 \%$ \\
\hline $\begin{array}{c}\text { Advanced HD-TRC } 3 \\
\text { (Case3) }\end{array}$ & $34.01 \%$ & $99.41 \%$ & $23.67 \%$ & $27.92 \%$ & $66.71 \%$ \\
\hline $\begin{array}{c}\text { Advanced HD-TRC } 4 \\
\text { (Case4) }\end{array}$ & $38.58 \%$ & $99.36 \%$ & $24.60 \%$ & $30.04 \%$ & $68.97 \%$ \\
\hline $\begin{array}{c}\text { Advanced HD-TRC } 5 \\
\text { (Case5) }\end{array}$ & $47.72 \%$ & $99.09 \%$ & $22.07 \%$ & $30.18 \%$ & $73.40 \%$ \\
\hline
\end{tabular}

690 
https://doi.org/10.5194/nhess-2020-295

Preprint. Discussion started: 9 October 2020

(C) Author(s) 2020. CC BY 4.0 License.

(c) (1)

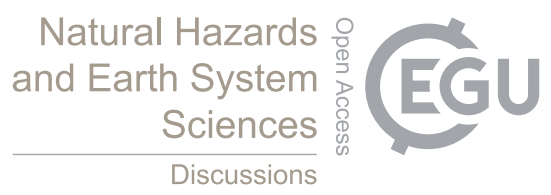

Table 14: Result of performance evaluation in Incheon-city

\begin{tabular}{|c|c|c|c|c|c|}
\hline Criteria & Sensitivity & Specificity & Precision & F1-score & AUC \\
\hline HRA of KMA & $6.90 \%$ & $99.97 \%$ & $73.68 \%$ & $12.61 \%$ & $53.43 \%$ \\
\hline HD-TRC & $27.09 \%$ & $99.40 \%$ & $39.01 \%$ & $31.98 \%$ & $63.25 \%$ \\
\hline $\begin{array}{c}\text { Advanced HD-TRC } 1 \\
\text { (Case1) }\end{array}$ & $30.05 \%$ & $99.31 \%$ & $38.13 \%$ & $33.61 \%$ & $64.68 \%$ \\
\hline $\begin{array}{c}\text { Advanced HD-TRC } 2 \\
\text { (Case2) }\end{array}$ & $46.80 \%$ & $98.70 \%$ & $33.69 \%$ & $39.18 \%$ & $72.75 \%$ \\
\hline $\begin{array}{c}\text { Advanced HD-TRC } 3 \\
\text { (Case3) }\end{array}$ & $49.75 \%$ & $98.43 \%$ & $30.89 \%$ & $38.11 \%$ & $74.09 \%$ \\
\hline $\begin{array}{l}\text { Advanced HD-TRC } 4 \\
\text { (Case4) }\end{array}$ & $55.17 \%$ & $98.30 \%$ & $31.37 \%$ & $40.00 \%$ & $76.74 \%$ \\
\hline $\begin{array}{c}\text { Advanced HD-TRC } 5 \\
\text { (Case5) }\end{array}$ & $61.08 \%$ & $97.58 \%$ & $26.27 \%$ & $36.74 \%$ & $79.33 \%$ \\
\hline
\end{tabular}

